\title{
A Combinatory Ferroelectric Compound Bridging Simple ABO3 and A-site-Ordered Qudruple Perovskite
}

Jianfa Zhao

Institute of Physics, Chinese Academy of Sciences

Jiacheng Gao

Institute of Physics

Wenmin Li

Chinese Academy of Sciences

Yuting Qian

Institute of Physics

Xudong Shen

Chinese Academy of Sciences

Xiao Wang

Max Planck Institute for Chemical Physics of Solids

Xi Shen

Institute of Physics, Chinese Academy of Sciences

Zhiwei Hu

Max Planck Institute for Chemical Physics of Solids https://orcid.org/0000-0003-0324-2227

Cheng Dong

Peking University Shenzhen graduate School

Qingzhen Huang

NIST center for neutron research

Lipeng Cao

Institute of Physics

Zhi Li

Nanjing University of Science and Technology

Jun Zhang

Institute of Physics

Chongwen Ren

Chinese Academy of Sciences

Lei Duan

Institute of Physics

Qingqing Liu 
IOPCAS

\section{Richeng Yu}

Institute of Physics

\section{Yang Ren}

Argonne National Laboratory https://orcid.org/0000-0001-9831-6035

\section{Shih-Chang Weng}

National Synchrotron Radiation Research Center

Hong-Ji Lin

National Synchrotron Radiation Research Center

\section{Chien-Te Chen}

National Synchrotron Radiation Research Center

\section{Liu Hao Tjeng}

Max Planck Institute for Chemical Physics of Solids https://orcid.org/0000-0002-0595-9312

\section{Youwen Long}

Institute of Physics https://orcid.org/0000-0002-8587-7818

\section{Zheng DENG}

Institute of Physics https://orcid.org/0000-0003-3921-1721

Jinlong Zhu

Department of Physics, Southern University of Science and Technology

\section{Xiancheng WANG}

Institute of Physics

\section{Hongming Weng}

Chinese Academy of Sciences https://orcid.org/0000-0001-8021-9413

\section{Runze Yu}

Institute of Physics https://orcid.org/0000-0001-9889-0299

\section{Martha Greenblatt}

Rutgers University

Changqing Jin ( $\sim$ Jin@iphy.ac.cn )

Chinese Academy of Sciences

\section{Article}

Keywords: ferroelectricity, symmetry breaking phase transition, qudruple perovskite, A-site-ordered perovskite, ferroelectric materials

Posted Date: September 9th, 2020

DOI: https://doi.org/10.21203/rs.3.rs-68865/v1 
License: (c) (i) This work is licensed under a Creative Commons Attribution 4.0 International License. Read Full License

Version of Record: A version of this preprint was published at Nature Communications on February 2nd, 2021. See the published version at https://doi.org/10.1038/s41467-020-20833-6. 


\section{A Combinatory Ferroelectric Compound Bridging Simple $\mathrm{ABO}_{3}$ and A-site-Ordered Qudruple Perovskite}

Jianfa Zhao ${ }^{1,2}$, Jiacheng Gao ${ }^{1}$, Wenmin $\mathrm{Li}^{1}$, Yuting Qian ${ }^{1}$, Xudong Shen ${ }^{1,2}$, Xiao Wang $^{3}$, Xi Shen ${ }^{1}$, Zhiwei Hu ${ }^{3}$, Cheng Dong ${ }^{4}$, Qingzhen Huang ${ }^{5}$, Lipeng Cao ${ }^{1}$, Zhi Li ${ }^{6}$, Jun Zhang ${ }^{1}$, Chongwen Ren ${ }^{1}$, Lei Duan ${ }^{1}$, Qingqing Liu ${ }^{1}$, Richeng $\mathrm{Yu}^{1}$, Yang Ren ${ }^{7}$, Shih-Chang Weng ${ }^{8}$, Hong-Ji Lin ${ }^{8}$, Chien-Te Chen ${ }^{8}$, Liu-Hao Tjeng ${ }^{3}$, Youwen Long ${ }^{1,2}$, Zheng Deng ${ }^{1}$, Jinlong Zhu ${ }^{9}$, Xiancheng Wang ${ }^{1}$, Hongming Weng ${ }^{1 *}$, Runze $\mathrm{Yu}^{{ }^{*}}$, Martha Greenblatt ${ }^{10}$, and Changqing Jin ${ }^{1,2 *}$

1.Beijing National Laboratory for Condensed Matter Physics, Institute of Physics; School of Physics Sciences, University of Chinese Academy of Sciences, Chinese Academy of Sciences, Beijing 100190, China;

2. Songshan Lake Materials Laboratory, Dongguan 523808, China

3. Max-Planck Institute for Chemical Physics of Solids, Nothnitzer Straße 40, 01187 Dresden, Germany

4. Peking University Shenzhen graduate School, School of Advanced Materials, Shenzhen, 518055, China

5. NIST Center for Neutron Research, National Institute of Standards and Technology, Gaithersburg, Maryland 20899, USA

6. School of Materials Science and Engineering, Nanjing University of Science and Technology, Nanjing 210094, China

7. Advanced Photon Source, Argonne National Laboratory, Argonne, Illinois 60439, USA

8. National Synchrotron Radiation Research Center, 101 Hsin-Ann Road, Hsinchu 30076, Taiwan

9. Department of Physics, Southern University of Science and Technology, Shenzhen 518055, China

10. Department of Chemistry and Chemical Biology, Rutgers University, 123 Bevier Road, Piscataway, NJ 08854 USA 
The simple $\mathrm{ABO}_{3}$ and $A$-site-ordered $\mathrm{AA}^{\prime}{ }_{3} \mathrm{~B}_{4} \mathrm{O}_{12}$ perovskites represent two types of the most classical perovskite-based functional materials. While there are well-known simple perovskites with ferroelectric properties, so far there is no report of ferrolectricity due to symmetry breaking transition in A-site-ordered quadruple perovskites, $\mathrm{AA}_{{ }_{3}} \mathrm{~B}_{4} \mathrm{O}_{12}$. Here we report the synthesis at high pressure and temperature of a new A-site-ordered perovskite, $\mathrm{PbHg}_{3} \mathrm{Ti}_{4} \mathrm{O}_{12}$. Remarkably, $\mathrm{PbHg}_{3} \mathrm{Ti}_{4} \mathrm{O}_{12}$ is the only known quadruple perovskite that transforms from a high-temperature centrosymmetric $(\mathrm{Im}-3)$, paraelectric phase to a low-temperature, non-centrosymmetric (Imm2) ferroelectric phase. Moreover, the average ionic radius of $\mathrm{A}$-site cations for $\mathrm{PbHg}_{3} \mathrm{Ti}_{4} \mathrm{O}_{12}$ is large $\sim 1.1 \AA$ and the tolerance factor $\boldsymbol{t}$ is about 0.88 . Surprisingly the coordination chemistry of $\mathbf{H g}^{2+}$ is changed from the usual square planar as in typical A-site-ordered quadruple perovskite to a rare stereo type with 8 ligands in $\mathrm{PbHg}_{3} \mathrm{Ti}_{4} \mathrm{O}_{12}$ driven via pressures. Thus $\mathrm{PbHg}_{3} \mathrm{Ti}_{4} \mathrm{O}_{12}$ appears to be a combinatory link from simple $\mathrm{ATiO}_{3}$ perovskite to $\mathrm{AA}_{3}^{\prime} \mathrm{Ti}_{4} \mathrm{O}_{12}$ type A-site-ordered perovskites, sharing both displacive ferroelectricity with the former and the structure coordination with the latter. This is the first example of ferroelectricity due to a symmetry breaking phase transition in $\mathrm{AA}^{\prime}{ }_{3} \mathrm{~B}_{4} \mathrm{O}_{12}$-type $\mathrm{A}$-site-ordered perovskite, and opens a new direction to search for ferroelectric materials in combinatory perovskites. 
Perovskites and their derivatives show many interesting physical and chemical or mineral properties such as ferromagnetism, ferroelectricity, piezoelectricity, ion conductivity, photocatalysis and superconductivity ${ }^{1-18}$ that can be modified dramatically by the coordination chemistry for a given composition. There is a special class of perovskite-type materials with the general chemical formula $\mathrm{AA}_{3}^{\prime} \mathrm{B}_{4} \mathrm{O}_{12}$, named A-site-ordered, or quadruple perovskites, which received much attention owing to their fascinating structural and wide varieties of physical properties ${ }^{10}$, including colossal magnetoresistance under weak field ${ }^{11}$, charge disproportionation ${ }^{12}$ and giant dielectric constant over a wide temperature range ${ }^{13,14}$. For the simple $\mathrm{ABO}_{3}$ perovskite, the 12-fold coordinated A-site is often occupied by large size ions such as alkali metal, alkaline earth or lanthanide cations and the 6-fold coordinated B-site is often occupied by transition metals (TMs) to satisfy the so called tolerance factor $t=$ $\left(r_{A}+r_{O}\right) / \sqrt{ } 2\left(r_{B}+r_{O}\right)\left(r_{A}, r_{B}, \& r_{O}\right.$ represent for the ion radius of $A, B$, and $O$, respectively) with $t$ usually in the range of 0.75 to 1.05 for stable perovskite compounds ${ }^{1,18}$. However in the A-site-ordered perovskite $\mathrm{AA}_{3}{ }_{3} \mathrm{~B}_{4} \mathrm{O}_{12}$, three quarters of the A-site is substituted by a TM, A' with much smaller ionic radius ${ }^{16-19}$. Generally, TM ions with strong Jahn-Teller distortions like $\mathrm{Mn}^{3+}$ and $\mathrm{Cu}^{2+}$ preferentially occupy the $\mathrm{A}^{\prime}$-site with square-planar coordination ${ }^{20-24}$. The small $\mathrm{TM}$ ion at the $\mathrm{A}^{\prime}$-site causes the distortion of $\mathrm{BO}_{6}$ octahedron in $\mathrm{AA}_{3}^{\prime} \mathrm{B}_{4} \mathrm{O}_{12}$ perovskite, usually resulting in a cubic crystal structure with space group $I m-3^{25}$. From a structural point of view, the flexibility for tilting the $\mathrm{BO}_{6}$ octahedra in $\mathrm{AA}_{3}^{\prime} \mathrm{B}_{4} \mathrm{O}_{12}$ perovskite is limited in order to maintain the square-planar coordination at the originally 12-fold coordinated A-site in the simple perovskite structure ${ }^{21}$.

Ferroelectricity is one of the most important properties for application in actuators, sensors, and memory storage devices, etc. Large numbers of ferroelectric materials possess simple proverskite structures, such as $\mathrm{BaTiO}_{3}, \mathrm{PbTiO}_{3}, \mathrm{~Pb}(\mathrm{Ti}, \mathrm{Zr}) \mathrm{O}_{3}$, $\mathrm{BiFeO}_{3}{ }^{26-30}$. The origin of ferroelectricity is due to either the lone pair $6 s^{2}$ effect of cations $\left(\mathrm{Pb}^{2+}, \mathrm{Bi}^{3+}\right)$, or the second-order Jahn-Teller active cations with electron configuration of $d^{0}\left(\mathrm{Ti}^{4+}, \mathrm{Zr}^{4+}\right)$; these compounds are usually referred to as 
displacive-type ferroelectrics. However, ferroelectricity is seldom observed in $\mathrm{AA}_{3}{ }_{3} \mathrm{~B}_{4} \mathrm{O}_{12}$ type $\mathrm{A}$-site-ordered compounds, even when they contain second-order Jahn-Teller active cations or lone pair effect cations ${ }^{28}$. One reason for the absence of ferroelectricity in this series of compounds is the usual presence of a centrosymmetric structure, and the variation of temperature generally causes isostructural or centrosymmetric - to - centrosymmetric phase transition ${ }^{12,21,25}$, hence there cannot be spontaneous polarization. Currently the rare examples in this series that show ferroelectricity are $\mathrm{AMn}_{7} \mathrm{O}_{12}(\mathrm{~A}=\mathrm{Ca}, \mathrm{Bi} \text { or } \mathrm{Pb})^{31-33}$ and $\mathrm{AMn}_{3} \mathrm{Cr}_{4} \mathrm{O}_{12}(\mathrm{~A}=\mathrm{La} \text { or } \mathrm{Bi})^{20}$, 22. Although these compounds have centrosymmetric structures, all are spin-driven multiferroic systems, due to strong magnetoelectric coupling effects ${ }^{20,22,32}$. Up to now, there is still no report of ferrolectricity from symmetry breaking transition in A-site-ordered perovskite compounds.

In this work, a new $\mathrm{AA}^{\prime}{ }_{3} \mathrm{~B}_{4} \mathrm{O}_{12}$ type A-site-ordered perovskite oxide, $\mathrm{PbHg}_{3} \mathrm{Ti}_{4} \mathrm{O}_{12}$ (henceforth PHTO) was designed and synthesized at high pressure and high temperature conditions. It is found that the $\mathrm{Hg}^{2+}$ ion occupies the $\mathrm{A}^{\prime}$-site in $\mathrm{AA}_{3}{ }_{3} \mathrm{~B}_{4} \mathrm{O}_{12}$ type perovskite in sharp contrast to previous reports where $3 d \mathrm{TM}$ ions $\left(\mathrm{Cu}^{2+}, \mathrm{Mn}^{3+}\right)$ usually locate at the $\mathrm{A}^{\prime}$-site. Moreover, ferroelectricity was observed in PHTO, when its ambient centrosymmetric phase transformed to a non-centrosymmetric phase at $250 \mathrm{~K}$. The origins of ferroelectricity are discussed based on the comprehensive characterizations of crystal structure using both neutron and synchrotron x-ray diffractions and density functional theory (DFT) calculation.

\section{Results and discussion}

Crystal structure. The NPD refinements are shown in Figure 1a, which confirm that PHTO crystallizes in the $\mathrm{AA}^{\prime}{ }_{3} \mathrm{~B}_{4} \mathrm{O}_{12}$ type A-site-ordered perovskite. The refined structure parameters of PHTO based on NPD data collected at $295 \mathrm{~K}$ are listed in Table 1. No anomaly is observed in the occupation parameters at any site, including full occupancy for the oxygen site as well. Thus, PHTO should have stoichiometric composition. Bond valence sum (BVS) calculations based on the refined structure from NPD data give valences of +2.26 for $\mathrm{Pb}$ ions, +1.99 for $\mathrm{Hg}$ ions and +3.88 for $\mathrm{Ti}$ 
ions (see Table 1), which are consistent with x-ray absorption spectroscopy (XAS) results discussed later. Moreover, for $\mathrm{Hg}$ ions, if one considers the four nearestneighbor $\mathrm{O}$ atoms $(\mathrm{Hg}-\mathrm{O}(\times 4)=2.320(5) \AA)$, the BVS value is only 1.56. However, if one takes into accounbts the four next-nearest-neighbour $\mathrm{O}$ atoms $(\mathrm{Hg}-\mathrm{O}(\times 4)=2.798(1)$ $\AA$ ) additionally, the BVS value is 1.99 . Therefore, $\mathrm{Hg}$ ions at $\mathrm{A}^{\prime}$-site are close to 8 -coordinated by $\mathrm{O}$, in sharp contrast to typical A-site-ordered perovskite where the $\mathrm{A}^{\prime}$-site is usually 4-coordinated by $\mathrm{O}$. Hence the obtained sample is an A-site-ordered perovskite with stoichiometric $\mathrm{Pb}^{2+} \mathrm{Hg}^{2+}{ }_{3} \mathrm{Ti}^{4+}{ }_{4} \mathrm{O}_{12}$ formula and space group $\mathrm{Im}-3$ as shown in Figure 1b. The structure model is consistent with the refinements of SXRD data as shown in Figure S1. Note that, the PHTO sample is single phase of high quality, no detectable diffraction peak belonging to $\mathrm{PbTiO}_{3}$ or $\mathrm{HgTiO}_{3}$ was found in either NPD or SXRD patterns.

As aforementioned, usually the strong Jahn-Teller active ions, like $\mathrm{Cu}^{2+}$ and $\mathrm{Mn}^{3+}$, are preferentially accommodated into the square-coordinated $\mathrm{A}^{\prime}$-site in the A-site-ordered perovskites, as in $\mathrm{LaCu}_{3} \mathrm{Fe}_{4} \mathrm{O}_{12}$ and $\mathrm{BiMn}_{3} \mathrm{Cr}_{4} \mathrm{O}_{12}{ }^{20,21}$. Some other TM ions have been recently introduced at the $\mathrm{A}^{\prime}$-site such as in $\mathrm{CaCo}_{3} \mathrm{~V}_{4} \mathrm{O}_{12}{ }^{37}$, $\mathrm{CaFe}_{3} \mathrm{Ti}_{4} \mathrm{O}_{12}{ }^{38}, \mathrm{CaPd}_{3} \mathrm{Ti}_{4} \mathrm{O}_{12}{ }^{39}$. Thus PHTO is the first known $\mathrm{AA}_{3}{ }_{3} \mathrm{~B}_{4} \mathrm{O}_{12}$-type perovskites with the $\mathrm{A}^{\prime}$-site fully occupied by $\mathrm{Hg}^{2+}$, other than $3 d \mathrm{TM}$, or Pd as shown in Table 2. The lattice parameter $(7.72 \AA)$ of PHTO is larger compared to those of other $\mathrm{AA}_{3}{ }_{3} \mathrm{~B}_{4} \mathrm{O}_{12}$ type perovskites (7.3-7.5 $\AA$ ), while the $\angle \mathrm{Ti}-\mathrm{O}-\mathrm{Ti}$ angle $\left(155.8^{\circ}\right)$ of PHTO is less distorted from the ideal $180^{\circ}$ than those for other $\mathrm{AA}^{\prime}{ }_{3} \mathrm{~B}_{4} \mathrm{O}_{12}$ type perovskites $\left(\angle B-O-B \approx 140^{\circ}\right)$. The larger $\angle \mathrm{Ti}-\mathrm{O}-\mathrm{Ti}$ angle and correspondingly smaller $\angle \mathrm{A}^{\prime}-\mathrm{O}-\mathrm{Ti}$ angle in PHTO imply the less tilting of $\mathrm{TiO}_{6}$ octahedron, which is attributed to the large ionic size of $\mathrm{Hg}^{2+}$ about $0.96 \AA$. Figure 2 shows the tolerance factor $t$ versus average ionic radius of A-site ions for simple perovskites $\mathrm{ATiO}_{3}$ and A-site-ordered perovskites $\mathrm{AA}_{3}{ }_{3} \mathrm{Ti}_{4} \mathrm{O}_{12}$ where the $t$ factor is calculated assuming a simple $\mathrm{ABO}_{3}$ form with the average ionic size at $\mathrm{A}$ site. It is found that from $\mathrm{CaTiO}_{3}$ to $\mathrm{BaTiO}_{3}$, the ionic radius of A-site increases from $1.34 \AA$ to $1.61 \AA$ while the tolerance factor $t$ increases from 0.97 to 1.07 . The simple perovskites $\mathrm{ATiO}_{3}$ are 
located at the upper right panel of Figure 2. For most of the $\mathrm{AA}^{\prime}{ }_{3} \mathrm{Ti}_{4} \mathrm{O}_{12}$ compounds, the average ionic radius of A-site is about $0.8 \AA$ and the tolerance factor $t$ is around 0.77. Therefore, $\mathrm{AA}_{3}^{\prime} \mathrm{Ti}_{4} \mathrm{O}_{12}$ perovskites are located at the lower left panel of the Figure 2. However, different from these $\mathrm{ATiO}_{3}$ and $\mathrm{AA}_{3}^{\prime} \mathrm{Ti}_{4} \mathrm{O}_{12}$ compounds, the average ionic radius of A-site ion for PHTO is large, about $1.1 \AA$ and the tolerance factor $t$ is about 0.88 . Moreover as aforementioned, the coordination number for $\mathrm{Hg}$ ions at the $\mathrm{A}^{\prime}$-site in $\mathrm{PHTO}$ is eight, not square planar as in $\mathrm{A}^{\prime}$-TM quadruple perovskites $\mathrm{AA}_{3}^{\prime} \mathrm{Ti}_{4} \mathrm{O}_{12}$, and it is located in the middle area of Fig. 2, between those of simple $\mathrm{ATiO}_{3}$ (coordination number 12) and $\mathrm{AA}_{3}^{\prime} \mathrm{Ti}_{4} \mathrm{O}_{12}$ quadruple perovskites (coordination number 4). Thus, PHTO appears to be a link from simple $\mathrm{ATiO}_{3}$ perovskite to $\mathrm{AA}_{3}^{\prime} \mathrm{Ti}_{4} \mathrm{O}_{12}$ type A-site-ordered perovskite (Figure 2).

Valence state analysis. The soft X-ray absorption spectrum at the $3 d \mathrm{TM}$ elements $L_{2,3}$ edges is highly sensitive to their valence state ${ }^{40,41}$ and local environment ${ }^{42}$ as well as orbital occupation ${ }^{43}$. Figure 3 a shows the Ti- $L_{2,3}$ XAS spectra of PHTO together with $\mathrm{SrTiO}_{3}$ as a pure $\mathrm{Ti}^{4+}$ reference. The very similar multiplet spectral features in PHTO and $\mathrm{SrTiO}_{3}$ clearly correspond to the Ti $2 p^{6} 3 d^{0} \rightarrow 2 p^{5} 3 d^{1}$ transition ${ }^{44,} 45$, demonstrating the $\mathrm{Ti}^{4+}$ valence state in PHTO. Note that the PHTO spectrum is shifted by about $0.25 \mathrm{eV}$ to lower energy with respect to the $\mathrm{SrTiO}_{3}$ spectrum, reflecting the different Ti local environments. Actually the Ti-O distance is 1.974(7) $\AA$ in PHTO and 1.951(7) $\AA$ in $\mathrm{SrTiO}_{3}{ }^{46}$, which suggests a weaker crystal field effect in PHTO. Figure $3 b$ shows the $\mathrm{Pb}-L_{3} \mathrm{XAS}$ spectra of $\mathrm{PHTO}$ together with $\mathrm{PbTiO}_{3}$ as a $\mathrm{Pb}^{2+}$ and $\mathrm{PbNiO}_{3}$ as $\mathrm{Pb}^{4+}$ reference. The weak pre-edge feature in $\mathrm{PbNiO}_{3}$ due to excitation from a $2 p$ core electron to the $6 s$ orbital. It has been established that this weak pre-edge feature is a sensitive finger-print of the $\mathrm{Pb}$ valence state in solid state materials ${ }^{47}$. The reason is that the $\mathrm{Pb} 5 d^{10}$ orbitals are fully occupied, the valence state is then reflected by the $6 s$ occupation. However, as shown in the inset, PHTO has the $\mathrm{Pb}-L_{3}$ XAS profile similar to the $\mathrm{Pb}^{2+}$ reference $\mathrm{PbTiO}_{3}$ in detail, no $2 p-6 s$ related excitation is observed in PHTO, which indicates the valence state of $\mathrm{Pb}^{2+}$ with fully occupied $6 s^{2}$ state in this compound. The XAS results show that the electronic 
configuration of PHTO is $\mathrm{Pb}^{2+} \mathrm{Hg}^{2+}{ }_{3} \mathrm{Ti}^{4+}{ }_{4} \mathrm{O}_{12}$, which is fully consistent with the BVS results based on the crystal structure.

Magnetic and transport characterizations. The magnetic susceptibility $\chi$ is almost constant and negative near zero from $300 \mathrm{~K}$ to $30 \mathrm{~K}$, while $\chi$ increases rapidly on further decrease of temperature as shown in Figure S2. These results reveale that PHTO is nonmagnetic due to the $3 d^{0}, 5 d^{10}$ and $6 s^{2}$ electron configuration for $\mathrm{Ti}^{4+}$, $\mathrm{Hg}^{2+}$ and $\mathrm{Pb}^{2+}$, respectively, and consistent with the BVS calculations and XAS results. The resistance of PHTO at room temperature is too large to be measured, indicating the high electrical insulating property and few vacancies in the sample. Figure S3a shows the Ultraviolet-Visible-Near Infrared (UV-Vis-NIR) absorption spectrum of PHTO. The curve exhibits a steep decrease from 420 to $640 \mathrm{~nm}$, which is a typical optical response of semiconductors. The optical band gap of the PHTO was estimated to be $2.12 \mathrm{eV}$. The first principle calculations show that PHTO is a direct gap insulator with $1.70 \mathrm{eV}$ gap at the $H$ point shown in Figure S3b. The gap might be underestimated in DFT calculations, nevertheless, it reveals the wide gap nature of PHTO. The obtained PHTO sample is stable at ambient up to $973 \mathrm{~K}$ as revealed by thermogravimetry analysis measurements shown in Figure S4.

Dielectricity and ferroelectricity. The permittivity and dielectric loss measured with different frequencies from $2 \mathrm{~K}$ to $300 \mathrm{~K}$ are shown in Figure $4 \mathrm{a}$ and $4 \mathrm{~b}$, respectively. The relative dielectric constant, $\varepsilon_{r}$ of PHTO is over 220 in the measured temperature range. The temperature dependence of $\varepsilon_{\mathrm{r}}$ shows a clear peak around $250 \mathrm{~K}$ at all the frequencies of measurements. The overall temperature-dependent $\varepsilon_{r}$ strongly indicates a low-temperature ferroelectric phase transition to a high-temperature paraelectric phase at $T_{\mathrm{FE}} \approx 250 \mathrm{~K}$. Furthermore, the transition temperature is independent of measurement frequency, indicating that PHTO is not a relaxor-type ferroelectric material. In order to further identify the ferroelectricity of PHTO, the isothermal polarizations were measured by the PUND method ${ }^{20}$. No loops of polarization versus electric field $(P-E)$ were observed in polycrystalline PHTO at room temperature. However, canonical $P-E$ hysteresis loops were observed below $250 \mathrm{~K}$ as shown in 
Figure $4 \mathrm{c}$ and $4 \mathrm{~d}$. It is clear that polarization is enhanced at low temperature. At fixed temperature, the $P-E$ loops significantly expand with increasing electric field. For example, the $P$ value increases from 0.028 to $0.11 \mu \mathrm{C} \mathrm{cm}^{-2}$ as the maximum electric field changes from 17 to $32 \mathrm{kV} \mathrm{cm}^{-1}$ at $10 \mathrm{~K}$. As known, $\mathrm{PbTiO}_{3}$ is a classic and extensively studied ferroelectric material with Curie temperature about $763 \mathrm{~K}$, which excludes the possibility that the ferroelectricity of $\mathrm{PHTO}$ originated from $\mathrm{PbTiO}_{3}$. Thus it can be concluded that the ferroelectricity is due to PHTO.

Temperature dependent crystal structure transition.To further understand the mechanism of ferroelctricity from the structure point of view, we performed the temperature dependent SXRD, as shown in Figure S5. The characteristic (400) diffraction peak at different temperatures is collected in Figure 5a. It is obvious that the diffraction peaks split into two sub-peaks between $240 \mathrm{~K}$ and $260 \mathrm{~K}$, which indicates the occurrence of temperature induced phase transition at $250 \mathrm{~K}$ is due to symmetry reduction from a cubic - to - orthorhombic phase. Checking the SXRD data measured at $300 \mathrm{~K}$ and $90 \mathrm{~K}$, all the high symmetry diffraction peaks, such as (200), (220), (222), (400) and (402) of the high temperature phase, are split into two sub-peaks on cooling to low temperature (see Figure S6). There is a clear long-range structural transition with decreasing temperature. The SXRD data collected at $90 \mathrm{~K}$ is presented in Figure 5b. The crystal structure of PHTO can be fitted very well by a orthorhombic phase of non-centrosymmetric space group Imm2 (No.44). The inset shows the crystal structure of the low temperature phase. The Rietveld refinement results are listed in Table S2. Figure 5c shows variation of the lattice parameters based on refinements of SXRD data. The lattice parameter $a$ decreases lineally from $300 \mathrm{~K}$ to $250 \mathrm{~K}$. Below the temperature of the phase transition, the lattice parameter $b$ and $c$ continue to decrease while parameter $a$ increases. Figure $5 \mathrm{~d}$ shows the evolution of $\mathrm{TiO}_{6}$ octahedron before and after phase transition. In the high temperature phase, $\mathrm{TiO}_{6}$ forms a regular octahedron with $\angle \mathrm{Ti}-\mathrm{O}-\mathrm{Ti}$ angle of $155.8^{\circ}$ and $\mathrm{Ti}-\mathrm{O}$ bond length of $1.974 \AA$ respectively. When this cubic phase transformed to an orthorhombic non-centrosymmetric phase below $250 \mathrm{~K}$, both $\angle \mathrm{Ti}-\mathrm{O}-\mathrm{Ti}$ angles and 
Ti-O bond lengths divergences occurred in $\mathrm{TiO}_{6}$ octahedron. These distortions originate from the relative displacements of $\mathrm{Ti}$ and $\mathrm{O}$ around all the axis directions. The polarization in the $a b$-plane was canceled due to the random relative displacements of $\mathrm{Ti}$ and $\mathrm{O}$, leaving the polarization vector only along the [001] direction. Therefore, PHTO is a displacive-type ferroelectric. The ionic spontaneous polarization can be calculated by multiplying the effective charges and the distance between the negative and positive valence weighted mean center along the $c$-axis then divided by the volume of the unit cell ${ }^{48}$. Based on the refined results of NPD data collected at $5 \mathrm{~K}$ in Table 3 , the calculated polarization value is about $13.65 \mu \mathrm{C} \mathrm{cm}^{-2}$. Although temperature-dependent phase transition is typical in A-site-ordered perovskites, it is usually isostructural or centrosymmetric - to - centrosymmetric phase transition from $I m-3$ to $P n-3$. Most of those phase transitions are mainly induced by charge transfer between the $\mathrm{A}^{\prime}$-site and B-site ions or charge disproportionation at B-site ions ${ }^{12,21,25}$. PHTO is the first example of $\mathrm{AA}_{3}^{\prime} \mathrm{B}_{4} \mathrm{O}_{12}$ type A-site-ordered perovskite that exhibits a centrosymmetric to non-centrosymmetric phase transition.

First principles calculations. In order to get a deeper insight into the ferroelectricity of PHTO at low temperature, first principles calculations have been performed. Figure S7 shows the phonon spectrum for the cubic structure of PHTO: three imaginary frequency modes with irreducible representation $T_{u}$ are degenerate at $\Gamma$ point. By moving atoms along these soft phonon modes the non-centrosymmetric crystal structure of $I m m 2$ space group can be obtained. Free energy per primitive cell versus moving and phonon amplitude of atoms along one of the soft modes is plotted in Figure 6. The energy well suggests a spontaneous transition with the biggest contribution from the Ti-O mode. The imaginary modes at $H$ point only consist of the Ti-O phonon modes, which confirms the experimental conclusion. In addition, the $6 s^{2}$ lone pair electrons of $\mathrm{Pb}^{2+}$ also contributes to the site instability according to the theory analysis. However, the contribution from the lone pair mechanism does not play a dominant role from the energy perspective (see Figure 6), so it will not be considered in detail here. Using Berry phase method, the polarization of ferroelectric 
structure and Born effective charge have been calculated. The calculated polarization value is about $16.87 \mu \mathrm{C} \mathrm{cm}^{-2}$, which could also be obtained by multiplying the Born effective charge tensor with the corresponding atom displacements. This result is roughly in agreement with that ionic spontaneous polarization calculation result of $13.65 \mu \mathrm{C} \mathrm{cm}^{-2}$ based on neutron diffraction measurements; both values are larger than the experimental result. This is because the calculated value is based on single crystal data, while the experimental measured value is from a polycrystalline sample of randomly distributed grains. For example, in ceramic samples of $\mathrm{BiFeO}_{3}$, much lower values of about $8.9 \mu \mathrm{C} \mathrm{cm}^{-2}$ of polarization have been measured at room temperature while in single crystals the polarization is up to $60 \mu \mathrm{C} \mathrm{cm}^{-2}$ along [012] axis and 100 $\mu \mathrm{C} \mathrm{cm}$ along [001] axis ${ }^{49,50}$. Another reason for the low experimental value of polarization may be due to the grain boundary effect and/or leaking current issue preventing the application of maximum electric field in the experiment ${ }^{49,51}$.

\section{Conclusions}

A new A-site-ordered perovskite $\mathrm{PbHg}_{3} \mathrm{Ti}_{4} \mathrm{O}_{12}$ was successfully synthesized at high pressure and high temperature. $\mathrm{PbHg}_{3} \mathrm{Ti}_{4} \mathrm{O}_{12}$ is a nonmagnetic insulator with a direct energy gap of $\sim 2.12 \mathrm{eV}$ and relative dielectric constant larger than 220 . $\mathrm{PbHg}_{3} \mathrm{Ti}_{4} \mathrm{O}_{12}$ undergoes a transition from a high temperature centrosymmetric, cubic and paraelectric phase to a low-temperature, non-centrosymmetric, orthorhombic ferroelectric phase with a record high Curie temperature at $250 \mathrm{~K}$ for an A-site-ordered quadruple perovskite. The ferroelectric distortion is dominated by Ti-O phonon mode anomaly. Because of the large average size of the A-site cation $\sim 1.1 \AA$ in PHTO, the coordination of $\mathrm{Hg}^{2+}$ is not square planar as in typical A-site-ordered quadruple perovskites, but closer to 8 . Therefore PHTO can be considered to be structurally linking $\mathrm{ABO}_{3}$ simple and $\mathrm{AA}^{\prime}{ }_{3} \mathrm{~B}_{4} \mathrm{O}_{12}$ quadruple perovskites. The newly established A-site-ordered perovskites $\mathrm{AHg}_{3} \mathrm{~B}_{4} \mathrm{O}_{12}$ may provide a potential pathway to find a new class of ferroelectric materials of high Curie temperature. The work provides one of unique examples that high pressure synthesis can lead to new 
compounds with unique properties that are otherwise hard to get access at ambient. Moreover perovskites are the most abundant minerals in the broad lower Mantle of the Earth where high pressure is prevailing. Hence it might shed lights to further understand the coordination chemistry of perovskites like compounds at high pressures.

\section{Methods}

Sample fabrication. The polycrystalline sample of PHTO was synthesized by a solid state reaction under high pressure of $6 \mathrm{GPa}$ and high temperature of $1273 \mathrm{~K}$. The starting materials $\mathrm{HgO}$ (Aldrich, 99.0\% pure), $\mathrm{PbO}$ (Alfa, 99.995\% pure) and $\mathrm{TiO}_{2}$ (Alfa, 99.995\% pure) were mixed homogenously in a molar ratio 1:3:4 and pressed into a pellet with diameter of $6 \mathrm{~mm}$ in an argon gas protected glove box with oxygen and $\mathrm{H}_{2} \mathrm{O}$ level of less than $1 \mathrm{ppm}$. The pre-pressed pellet was sealed in a gold capsule. High pressure experiments were performed with the cubic anvil type high pressure apparatus $^{34,35}$. After the pressure was gradually increased to $6 \mathrm{GPa}$, the sample was heated to $1273 \mathrm{~K}$ and maintained for $30 \mathrm{~min}$. Then the temperature was quenched to ambient before the release of pressure. In this process, yellow polycrystalline PHTO was obtained.

Structure characterization. The crystal structure was characterized by neutron powder diffraction (NPD) with the BT-1 high-resolution neutron powder diffractometer with a Ge (311) monochromator at the Center for Neutron Research (NCNR) of the National Institute of Standard \& Technology (NIST). The neutron wavelength was $2.0774 \AA$. The intensities were measured with steps of $0.05^{\circ}$ in the $2 \theta$ range of $10^{\circ}-160^{\circ}$. The sample was also measured by synchrotron $\mathrm{x}$-ray diffraction (SXRD) at the 11-BM-B at the Advanced Photon Source (APS) in Argonne National Laboratory. The X-ray wavelength was $0.412726 \AA$. Diffraction data were collected in the angle $(2 \theta)$ range from $0.5^{\circ}$ to $50^{\circ}$ with steps of $0.002^{\circ}$. The obtained NPD and SXRD data were analyzed by the Rietveld method with the GSAS program ${ }^{36}$. 
Valences determination. The valence states of $\mathrm{Ti}$ and $\mathrm{Pb}$ ions were determined by X-ray absorption spectroscopy (XAS). The soft XAS at the Ti- $L_{2,3}$ edges was measured with total electron yield mode at the Dragon beamline while the hard XAS at the $\mathrm{Pb}-L_{3}$ edges were measured with transmission geometry at the BL07A beamline at National Synchrotron Radiation Research Center (NSRRC) of Taiwan. $\mathrm{SrTiO}_{3}$, $\mathrm{PbTiO}_{3}$ and $\mathrm{PbNiO}_{3}$ were also measured at the $\mathrm{Ti} L$-edge and $\mathrm{Pb} L$-edge as reference materials.

Permittivity and ferroelectricity characterization. The permittivity was measured with different frequency by an Agilent-4980A LCR meter on a solid pellet with 4.0 $\mathrm{mm}$ in diameter and $230 \mu \mathrm{m}$ in thickness. The ferroelectric hysteresis loops were measured at $20 \mathrm{~Hz}$ with a Radiant Precision Premier-II Ferroelectric Test System at different temperatures based on the proposed positive-up negative-down (PUND) method. Detailed experimental descriptions can be found in Ref. 20.

\section{REFERENCES}

(1) Goodenough, J.; Longo, J. Crystallographic and magnetic properties of perovskite and perovskite related compounds. Landolt-Bornstein Numerical Data and Functional Relationships in Science and Technologym, eds Hellwege K-H, Hellwege AM (Springer, Berlin) 1970, III/4, 126-314.

(2) Hayward, M. A.; Cussen, E. J.; Claridge, J. B.; Bieringer, M.; Rosseinsky, M. J.; Kiely, C. J.; Blundell, S. J.; Marshall, I. M.; Pratt, F. L., The hydride anion in an extended transition metal oxide array: LaSrCoO3H0.7. Science 2002, 295, 1882.

(3) Jin, C. Q.; Wu, X. J.; Laffez, P.; Tatsuki, T.; Tamura, T.; Adachi, S.; Yamauchi, H.; Koshizuka, N.; Tanaka, S. Superconductivity at $80 \mathrm{~K}$ in $(\mathrm{Sr}, \mathrm{Ca})_{3} \mathrm{Cu}_{2} \mathrm{O}_{4+\delta} \mathrm{Cl}_{2-\mathrm{y}}$ induced by apical oxygen doping. Nature 1995, 375, 301-303.

(4) Zhang, J. J.; Botana, A. S.; Freeland, J. W.; Phelan, D.; Zheng, H.; Pardo, V.; Norman, M. R.; Mitchell, J. F. Large orbital polarization in a metallic square-planar nickelate. Nat. Phys. 2017, $13,864-870$.

(5) Li, M. R.; Stephens, P. W.; Croft, M.; Deng, Z.; Li, W. M.; Jin, C. Q.; Retuerto, M.; Hodges, J. P.; Frank, C. E.; Wu, M. X.; Walker, D.; Greenblatt, M. $\mathrm{Mn}_{2}\left(\mathrm{Fe}_{0.8} \mathrm{Mo}_{0.2}\right) \mathrm{MoO}_{6}$ : a double perovskite with multiple transition metal sublattice magnetic effects. Chem. Mater. 2018, 30, 4508.

(6) Lin, J. F; Vanko, G; Jacobsen, S. D; Iota, V; Struzhkin, V. V; Prakapenka, V. B; Kuznetsov, A; Yoo, C, S. Spin transition zone in Earth's lower mantle. Science 2007, 317 1740-1743 
(7) Kageyama, H.; Hayashi, K.; Maeda, K.; Attfield, J. P.; Hiroi, Z.; Rondinelli, J. M.; Poeppelmeier, K. R., Expanding frontiers in materials chemistry and physics with multiple anions. Nat. Commun. 2018, 9, 772.

(8) Li. W. M., Zhao. J. F., Cao. L. P., Hu. Z., Huang. Q. Z., Wang. X. Liu. C., Y., Zhao. G. Q., Zhang. J., Liu. Q. Q., Yu. R. Z., Long. Y. W., Wu. H., Lin. H. J., Chen. C. T., Li. Z., Gong. Z. Z., Guguchia. Z., Kim. J. S., Stewart. G. R., Uemura. Y. J., Uchida. S. \& Jin. C. Q., "Superconductivity in a unique type of copper oxide", Proceedings of the National Academy of Sciences 2019, 116, 12156-12160.J

(9) in, C. Q.; Adachi, S.; Wu, X. J.; Yamauchi, H.; Tanaka, S. 117K Superconductivity in the Ba-Ca-Cu-O System. Physica C 223, 238-242 (1994)

(10) Shimakawa, Y. A-site-ordered perovskites with intriguing physical properties. Inorg. chem. 2008, 47, 8562-8570.

(11) Zeng, Z., Greenblatt, M., Subramanian, M. A.; Croft, M. Large low-field magnetoresistance in perovskite-type $\mathrm{CaCu}_{3} \mathrm{Mn}_{4} \mathrm{O}_{12}$ without double exchange. Phys. Rev. Lett. 1999, 82, 3164-3167.

(12) Yamada, I.; Takata, K.; Hayashi, N.; Shinohara, S.; Azuma, M.; Mori, S.; Muranaka, S.; Shimakawa, Y.; Takano, M. A perovskite containing quadrivalent iron as a charge-disproportionated ferrimagnet. Angew. Chem. Int. Ed. 2008, 47, 7032-7035.

(13) Ramirez, A. P.; Subramanian, M. A.; Gardel, M.; Blumberg, G.; Li, D.; Vogt, T.; Shapiro, S. M. Giant dielectric constant response in a copper-titanate. Solid State Commun. 2000, 115, 217-220.

(14) Arbatti, M.; Shan, X.; Cheng, Z. Y. Ceramic-polymer composites with high dielectric constant. Adv. Mater. 2007, 19, 1369-1372.

(15) Cheng, J. G.; Zhou, J. S.; Yang, Y. F.; Zhou, H. D.; Matsubayashi, K.; Uwatoko, Y.; MacDonald, A.; Goodenough, J. B. Possible Kondo physics near a metal-insulator crossover in the A-site ordered perovskite $\mathrm{CaCu}_{3} \mathrm{Ir}_{4} \mathrm{O}_{12}$. Phys. Rev. Lett. 2013, 111, 176403.

(16) Panda, P. K. Review: environmental friendly lead-free piezoelectric materials. J. Mater. Sci. 2009, 44, 5049-5062.

(17) Belik, A. A.; Glazkova, Y. S.; Katsuya, Y.; Tanaka, M.; Sobolev, A. V.; Presniakov, I. A. Low-temperature structural modulations in $\mathrm{CdMn}_{7} \mathrm{O}_{12}, \mathrm{CaMn}_{7} \mathrm{O}_{12}, \mathrm{SrMn}_{7} \mathrm{O}_{12}$, and $\mathrm{PbMn}_{7} \mathrm{O}_{12}$ perovskites studied by synchrotron X-ray powder diffraction and mossbauer spectroscopy. $J$. Phys. Chem. C 2016, 120, 8278-8288.

(18) Jin, C. Q.; Zhou, J. S.; Goodenough, J. B.; Liu, Q. Q.; Zhao, J. G.; Yang, L. X.; Yu, Y.; Yu, R. C.; Katsura, T.; Shatskiy, A.; Ito, E. High-pressure synthesis of the cubic perovskite $\mathrm{BaRuO}_{3}$ and evolution of ferromagnetism in $\mathrm{ARuO}_{3}(\mathrm{~A}=\mathrm{Ca}, \mathrm{Sr}, \mathrm{Ba})$ ruthenates. Proc. Natl. Acad. Sci. 2008, 105, 7115-7119.

(19) Deng, H. S.; Liu, M.; Dai, J. H.; Hu, Z. W.; Kuo, C. Y.; Yin, Y. Y.; Yang, J. Y.; Wang, X.; Zhao, Q.; Xu, Y. J.; Fu, Z. M.; Cai, J. W.; Guo, H. Z.; Jin, K. J.; Pi, T. W.; Soo, Y. L.; Zhou, G. H.; Cheng, J. G.; Chen, K.; Ohresser, P.; Yang, Y. F.; Jin, C. Q.; Tjeng, L. H.; Long, Y. W. 
Strong enhancement of spin ordering by A-site magnetic ions in the ferrimagnet $\mathrm{CaCu}_{3} \mathrm{Fe}_{2} \mathrm{Os}_{2} \mathrm{O}_{12}$. Phys. Rev. B 2016, 94, 024414.

(20) Zhou, L.; Dai, J. H.; Chai, Y. S.; Zhang, H. M.; Dong, S.; Cao, H. B.; Calder, S.; Yin, Y. Y.; Wang, X.; Shen, X. D.; Liu, Z. H.; Saito, T.; Shimakawa, Y.; Hojo, H.; Ikuhara, Y.; Azuma, M.; Hu, Z. W.; Sun, Y.; Jin, C. Q.; Long, Y. W. Realization of large electric polarization and strong magnetoelectric coupling in $\mathrm{BiMn}_{3} \mathrm{Cr}_{4} \mathrm{O}_{12}$. Adv. Mater. 2017, 29, 1703435.

(21) Long, Y. W.; Hayashi, N.; Saito, T.; Azuma, M.; Muranaka, S.; Shimakawa, Y. Temperature-induced A-B intersite charge transfer in an A-site-ordered $\mathrm{LaCu}_{3} \mathrm{Fe}_{4} \mathrm{O}_{12}$ perovskite. Nature 2009, 458, 60-63.

(22) Wang, X.; Chai, Y. S.; Zhou, L.; Cao, H. B.; Cruz, C.-D.; Yang, J. Y.; Dai, J. H.; Yin, Y. Y.; Yuan, Z.; Zhang, S.; Yu, R. Z.; Azuma, M.; Shimakawa, Y.; Zhang, H. M.; Dong, S.; Sun, Y.; Jin, C. Q.; Long, Y. W. Observation of magnetoelectric multiferroicity in a cubic perovskite system: $\mathrm{LaMn}_{3} \mathrm{Cr}_{4} \mathrm{O}_{12}$. Phys. Rev. Lett. 2015, 115, 087601.

(23) Yamada, I.; Etani, H.; Tsuchida, K.; Marukawa, S.; Hayashi, N.; Kawakami, T.; Mizumaki, M.; Ohgushi, K.; Kusano, Y.; Kim, J.; Tsuji, N.; Takahashi, R.; Nishiyama, N.; Inoue, T.; Irifune, T.; Takano, M. Control of bond-strain-induced electronic phase transitions in iron perovskites. Inorg. Chem. 2013, 52, 13751-13761.

(24) Yin, Y. Y; Liu, M.; Dai, J. H; Wang, X.; Zhou, L.; Cao, H. B.; dela Cruz, C.; Chen, C. T; Xu, Y.; Shen, X.; Yu, R.; Alonso, J. A.; Muñoz, A.; Yang, Y.-F; Jin, C.; Hu, Z.; Long, Y. W. $\mathrm{LaMn}_{3} \mathrm{Ni}_{2} \mathrm{Mn}_{2} \mathrm{O}_{12}$ : An A- and B-site ordered quadruple perovskite with A-site tuning orthogonal spin ordering. Chem. Mater. 2016, 28, 8988-8996.

(25) Long, Y. W.; Saito, T.; Tohyama, T.; Oka, K.; Azuma, M.; Shimakawa, Y. Intermetallic charge transfer in A-site-ordered double perovskite $\mathrm{BiCu}_{3} \mathrm{Fe}_{4} \mathrm{O}_{12}$. Inorg. Chem. 2009, 48, 8489-8492.

(26) Choi, K. J.; Biegalski, M.; Li, Y. L.; Sharan, A.; Schubert, J.; Uecker, R.; Reiche, P.; Chen, Y. B.; Pan, X. Q.; Gopalan, V.; Chen, L. Q.; Schlom, D. G.; Eom, C. B. Enhancement of ferroelectricity in strained $\mathrm{BaTiO}_{3}$ thin films. Science 2004, 306, 1005-1009.

(27) Kubel, F.; Schmid, H. Structure of a ferroelectric and ferroelastic monodomain crystal of the perovskite $\mathrm{BiFeO}_{3}$. Acta Crystallogr. B 1990, 46, 698-702.

(28) Aimi, A.; Mori, D.; Hiraki, K.; Takahashi, T.; Shan, Y. J.; Shirako, Y.; Zhou, J. S.; Inaguma, Y. High-pressure synthesis of A-site ordered double perovskite $\mathrm{CaMnTi}_{2} \mathrm{O}_{6}$ and ferroelectricity driven by coupling of A-site ordering and the second-order Jahn-Teller effect. Chem. Mater. 2014, 26, 2601-2608.

(29) Sawaguchi, E. Ferroelectricity versus antiferroelectricity in the solid solutions of $\mathrm{PbZrO}_{3}$ and $\mathrm{PbTiO}_{3}$. J. Phys. Soc. Jpn. 1953, 8, 615-629.

(30) Yamamoto, T. Ferroelectric properties of the $\mathrm{PbZrO}_{3}-\mathrm{PbTiO}_{3}$ system. Jpn. J. App.l Phys. 1996, 35, 5104-5108.

(31) Johnson, R. D.; Chapon, L. C.; Khalyavin, D. D.; Manuel, P.; Radaelli, P. G.; Martin, C. Giant improper ferroelectricity in the ferroaxial magnet $\mathrm{CaMn}_{7} \mathrm{O}_{12}$. Phys. Rev. Lett. 2012, 108, 067201 . 
(32) Belik, A. A.; Glazkova, Y. S.; Terada, N.; Matsushita, Y.; Sobolev, A. V.; Presniakov, I. A.; Tsujii, N.; Nimori, S.; Takehana, K.; Imanaka, Y. Spin-driven multiferroic properties of $\mathrm{PbMn}_{7} \mathrm{O}_{12}$ perovskite. Inorg. Chem. 2016, 55, 6169-6177.

(33) Mezzadri, F.; Calestani, G.; Calicchio, M.; Gilioli, E.; Bolzoni, F.; Cabassi, R.; Marezio, M.; Migliori, A. Synthesis and characterization of multiferroic $\mathrm{BiMn}_{7} \mathrm{O}_{12}$. Phys. Rev. B 2009, 79 $100106(\mathrm{R})$.

(34) Zhang, J.; Jia, Y. T.; Wang, X. C.; Li, Z.; Duan, L.; Li, W. M.; Zhao, J. F.; Cao, L. P.; Dai, G. Y.; Deng, Z.; Zhang, S. J.; Feng, S. M.; Yu, R. Z.; Liu, Q. Q.; Hu, J. P.; Zhu, J. L.; Jin, C. Q. A new quasi-one-dimensional compound $\mathrm{Ba}_{3} \mathrm{TiTe}_{5}$ and superconductivity induced by pressure. NPG Asia Materials 2019, 11, 60.

(35) Deng, Z.; Kang, C. J.; Croft, M.; Li, W. M.; Shen, X.; Zhao, J. F.; Yu, R. C.; Jin, C. Q.; Kotliar, G.; Liu, S. Z.; Tyson, T. A.; Tappero, R.; Greenblatt, M. A pressure-induced inverse order-disorder transition in double perovskites. Angew. Chem. Int. Ed. 2020, 59, 8240.

(36) Toby, B. H. EXPGUI, a graphical user interface for GSAS. J. Appl. Crystallogr. 2001, 34, 210-213.

(37) Ovsyannikov, S. V.; Bykova, E.; Pakhomova, A.; Kozlenko, D. P.; Bykov, M.; Kichanov, S. E.; Morozova, N. V.; Korobeinikov, I. V.; Wilhelm, F.; Rogalev, A.; Tsirlin, A. A.; Kurnosov, A. V.; Zainulin, Y. G.; Kadyrova, N. I.; Tyutyunnik, A. P.; Dubrovinsky, L. Structural and magnetic transitions in $\mathrm{CaCo}_{3} \mathrm{~V}_{4} \mathrm{O}_{12}$ perovskite at extreme conditions. Inorg. Chem. 2017, 56, 6251-6263.

(38) Leinenweber, K.; Linton, J.; Navrotsky, A.; Fei, Y.; Parise, J. B. High-pressure perovskites on the join $\mathrm{CaTiO}_{3}-\mathrm{FeTiO}_{3}$. Phys. Chem. Miner. 1995, 22, 251-258.

(39) Shiro, K.; Yamada, I.; Ikeda, N.; Ohgushi, K.; Mizumaki, M.; Takahashi, R.; Nishiyama, N.; Inoue, T.; Irifune, T. $\mathrm{Pd}^{2+}$-incorporated perovskite $\mathrm{CaPd}_{3} \mathrm{~B}_{4} \mathrm{O}_{12}(\mathrm{~B}=\mathrm{Ti}, \mathrm{V})$. Inorg. Chem. 2013, 52, 1604-1609.

(40) Schlappa, J.; Chang, C. F.; Hu, Z.; Schierle, E.; Ott, H.; Weschke, E.; Kaindl, G.; Huijben, M.; Rijnders, G.; Blank, D. H. A.; Tjeng, L. H.; Schussler-Langeheine, C. Resonant soft x-ray scattering from stepped surfaces of $\mathrm{SrTiO}_{3}$. J. Phys.: Condens. Matter. 2012, 24, 035501.

(41) Gegner, J.; Gamza, M.; Ackerbauer, S. V.; Hollmann, N.; Hu, Z.; Hsieh, H. H.; Lin, H. J.; Chen, C. T.; Ormeci, A.; Leithe-Jasper, A.; Rosner, H.; Grin, Y.; Tjeng, L. H. Insulator-metal transition in TiGePt: A combined photoelectron spectroscopy, x-ray absorption spectroscopy, and band structure study. Phys. Rev. B 2012, 85, 235106.

(42) Haverkort, M. W.; Hu, Z.; Tanaka, A.; Ghiringhelli, G.; Roth, H.; Cwik, M.; Lorenz, T.; Schussler-Langeheine, C.; Streltsov, S. V.; Mylnikova, A. S.; Anisimov, V. I.; de Nadai, C.; Brookes, N. B.; Hsieh, H. H.; Lin, H. J.; Chen, C. T.; Mizokawa, T.; Taguchi, Y.; Tokura, Y.; Khomskii, D. I.; Tjeng, L. H. Determination of the orbital moment and crystal-field splitting in $\mathrm{LaTiO}_{3}$. Phys. Rev. Lett. 2005, 94, 056401.

(43) Chang, C. F.; Koethe, T. C.; Hu, Z.; Weinen, J.; Agrestini, S.; Zhao, L.; Gegner, J.; Ott, H.; Panaccione, G.; Wu, H.; Haverkort, M. W.; Roth, H.; Komarek, A. C.; Offi, F.; Monaco, G.; Liao, Y. F.; Tsuei, K. D.; Lin, H. J.; Chen, C. T.; Tanaka, A.; Tjeng, L. H. c-axis dimer and its electronic breakup: the insulator-to-metal transition in $\mathrm{Ti}_{2} \mathrm{O}_{3}$. Phys. Rev. X 2018, 8, 021004. 
(44) Degroot, F. M. F.; Fuggle, J. C.; Thole, B. T.; Sawatzky, G. A. $L_{2,3}$ X-ray-absorption edges of d $\mathrm{d}^{0}$ compounds: $\mathrm{K}^{+}, \mathrm{Ca}^{2+}, \mathrm{Sc}^{3+}$ and $\mathrm{Ti}^{4+}$ in $\mathrm{O}_{h}$ (octahedral) symmetry. Phys. Rev. B 1990, 41, 928-937.

(45) Pichler, T.; Hu, Z.; Grazioli, C.; Legner, S.; Knupfer, M.; Golden, M. S.; Fink, J.; de Groot, F. M. F.; Hunt, M. R. C.; Rudolf, P.; Follath, R.; Jung, C.; Kjeldgaard, L.; Bruhwiler, P.; Inakuma, M.; Shinohara, H. Proof for trivalent Sc ions in $\mathrm{Sc}_{2} @ \mathrm{C}_{84}$ from high-energy spectroscopy. Phys. Rev. B 2000, 62, 13196-13201.

(46) Yamanaka, T.; Hirai, N.; Komatsu, Y. Structure change of $\mathrm{Ca}_{1-\mathrm{x}} \mathrm{Sr}_{\mathrm{x}} \mathrm{TiO}_{3}$ perovskite with composition and pressure. Am. Mineral. 2002, 87, 1183-1189.

(47) Chen, K.; Mijiti, Y.; Agrestini, S.; Liao, S. C.; Li, X.; Zhou, J. S.; Di Cicco, A.; Baudelet, F.; Tjeng, L. H.; Hu, Z. Valence state of $\mathrm{Pb}$ in transition metal perovskites $\mathrm{PbTMO}_{3}(\mathrm{TM}=\mathrm{Ti}, \mathrm{Ni})$ determined from X-ray absorption near-edge spectroscopy. Phys. Status Solidi B 2018, 255, 1800014

(48) Zhu, J. L.; Han, W.; Zhang, J. Z.; Xu, H. W.; Vogel, S. C.; Jin, C. Q.; Izumi, F.; Momma, K.; Kawamura, Y.; Zhao, Y. S. Nuclear and charge density distributions in ferroelectric $\mathrm{PbTiO}_{3}$ : maximum entropy method analysis of neutron and X-ray diffraction data. Powder. Diffr. 2013, 28, 276-280.

(49) Lebeugle, D.; Colson, D.; Forget, A.; Viret, M. Very large spontaneous electric polarization in $\mathrm{BiFeO}_{3}$ single crystals at room temperature and its evolution under cycling fields. Appl. Phys. Lett. 2007, 91, 022907.

(50) Wang, Y. P.; Yuan, G. L.; Chen, X. Y.; Liu, J. M.; Liu, Z. G. Electrical and magnetic properties of single-phased and highly resistive ferroelectromagnet $\mathrm{BiFeO}_{3}$ ceramic. J. Phys. D Appl. Phys. 2006, 39, 2019-2023.

(51) Lebeugle, D.; Colson, D.; Forget, A.; Viret, M.; Bonville, P.; Marucco, J. F.; Fusil, S. Room-temperature coexistence of large electric polarization and magnetic order in $\mathrm{BiFeO}_{3}$ single crystals. Phys. Rev. B 2007, 76, 024116.

\section{Acknowledgements}

This work was supported by NSF\& MOST of China through research projects.

\section{Author contributions}

C. Q. J. conceived the project. C. Q. J. R. Z. Y. H. M. W. coordinated the research. J. F. Z., X. W., W. M. L., J. Z., Z.D., L. D., C. W. R, Y. W. L., J. L. Z., R. Z. Y., X. C. W. synthesized the samples and performed the major measurements. X. D. S., J. F. Z. and Y. W. L. carried out the dielectric and ferroelectric measurements with the help of others. J. F. Z., Y. R., R. Z. Y., C. Q. J. and C. D. performed the X-ray diffraction and crystal structure analysis. Q. Z. H. and J. F. Z. collected the powder neutron 
diffraction data and carried out the data analysis with the help of others. X. S. and R. C. Y. carried the TEM measurements. J. F. Z., Z. W. H., L. P. C., W. M. L., H. J. L., C. T. C. and L. H. T. carried out the XAS measurements. J. C. G., Y. T. Q., Z. L. and H. M. W. did the theoretical calculations. J. F. Z., R. Z. Y., C. Q. J. discussed with M. G. the experimental results in many details. J. F. Z., R. Z. Y. and C. Q. J. wrote the manuscript with comments from M. G. All authors contributed to this version.

\section{Competing interests}

The authors declare no competing interests.

\section{Data and materials availability}

All data needed to evaluate the conclusions in the paper are present in the paper and the supplementary materials. 
Table 1 | Refined structure parameters of PHTO based on NPD data collected at $295 \mathrm{~K}$.

\begin{tabular}{ll}
\hline & NPD \\
\hline $\mathrm{a}(\AA)$ & $7.7283(2)$ \\
$\mathrm{Z}$ & 2 \\
Formula weight & 1192.56 \\
Cacl. Density $\left(\mathrm{g} / \mathrm{cm}^{3}\right)$ & $8.5800(2)$ \\
$\mathrm{V}\left(\AA^{3}\right)$ & $461.57(9)$ \\
$\mathrm{O}_{\mathrm{y}}$ & $0.7155(1)$ \\
$\mathrm{O}_{\mathrm{z}}$ & $0.2090(7)$ \\
$U_{\text {iso }}(\mathrm{Pb})\left(\AA^{2}\right)$ & $0.009(5)$ \\
$U_{\text {iso }}(\mathrm{Hg})\left(\AA^{2}\right)$ & $0.014(2)$ \\
$U_{\text {iso }}(\mathrm{Ti})\left(\AA^{2}\right)$ & $0.010(0)$ \\
$U_{\text {iso }}(\mathrm{O})\left(\AA^{2}\right)$ & $0.014(0)$ \\
$\mathrm{Pb}-\mathrm{O}(\times 12)(\AA)$ & $2.728(5)$ \\
$\mathrm{Hg}-\mathrm{O}(\times 4)(\AA)$ & $2.320(5)$ \\
$\mathrm{Hg}-\mathrm{O}(\times 4)(\AA)$ & $2.798(1)$ \\
$\mathrm{Ti}-\mathrm{O}(\times 6)(\AA)$ & $1.975(8)$ \\
$\angle \mathrm{Ti}-\mathrm{O}-\mathrm{Ti}\left({ }^{\circ}\right)$ & $155.83(6)$ \\
$\mathrm{BVS}(\mathrm{Pb})$ & 2.26 \\
$\mathrm{BVS}(\mathrm{Hg})$ & 1.99 \\
$\mathrm{BVS}(\mathrm{Ti})$ & 3.88 \\
$\mathrm{R}_{\mathrm{wp}}(\%)$ & 4.56 \\
$\mathrm{R}_{\mathrm{p}}(\%)$ & 4.12 \\
\hline
\end{tabular}

${ }^{a}$ The BVS values $\left(V_{i}\right)$ were calculated using the formula $V_{i}=\Sigma_{j} S_{i j}$, and $\left.S_{i j}=\exp \left[\left(r_{0}-r_{i j}\right) / 0.37\right)\right]$. In PHTO, $r_{0}=2.112$ for $\mathrm{Pb}, 1.972$ for $\mathrm{Hg}$ and 1.815 for Ti. For the A-site $\mathrm{Pb}, 12$-coordinated oxygen atoms were used. For the $\mathrm{A}^{\prime}$-site $\mathrm{Hg}, 8$-coordinated oxygen atoms were used. For the B-site Ti, 6-coordinated oxygen atoms were used. ${ }^{b}$ Space group: $\mathrm{Im}$-3; Atomic sites: $\mathrm{Pb} 2 a(0,0,0), \mathrm{Hg} 6 b$ $(0,0.5,0.5)$, Ti $8 c(0.25,0.25,0.25), \mathrm{O} 24 g(0, y, \mathrm{z})$.

Table 2 | Lattice constant $a$, ionic radius of $\mathrm{A}$-site $\boldsymbol{r}_{\mathrm{A}}$, ionic radius of $\mathrm{A}^{\prime}$-site $\boldsymbol{r}_{\mathrm{A}^{\prime}}$, difference between ionic radii of $\mathrm{A}^{-}$and $\mathrm{A}^{\prime}$-site ions $\Delta r_{\mathrm{A}}$, metal-oxygen bond angles $\angle$ $\mathrm{A}^{\prime}-\mathrm{O}-\mathrm{Ti}$ and $\angle \mathrm{Ti}-\mathrm{O}-\mathrm{Ti}$ for some $\mathrm{AA}^{\prime}{ }_{3} \mathrm{Ti}_{4} \mathrm{O}_{12}$ type perovskite compounds. ${ }^{33}$

\begin{tabular}{lcccccc}
\hline Compounds & $\boldsymbol{a} / \AA$ & $\boldsymbol{r}_{\mathbf{A}} / \AA$ & $\boldsymbol{r}_{\mathrm{A}^{\prime}} / \AA$ & $\Delta \boldsymbol{r}_{\mathbf{A}} / \AA$ & $\angle \mathbf{A}^{\prime}-\mathbf{O}-\mathbf{T i} / \mathbf{d e g}$ & $\angle \mathbf{T i}-\mathbf{O}-\mathbf{T i} / \mathbf{d e g}$ \\
\hline $\mathbf{P b H g}_{3} \mathbf{T i}_{4} \mathbf{O}_{\mathbf{1 2}}$ & 7.7234 & 1.49 & 0.96 & 0.53 & 102.60 & 154.22 \\
$\mathbf{C a P d}_{\mathbf{3}} \mathbf{T i}_{\mathbf{4}} \mathbf{O}_{\mathbf{1 2}}$ & 7.4977 & 1.34 & 0.64 & 0.70 & 107.17 & 144.93 \\
$\mathbf{C a F e}_{\mathbf{3}} \mathbf{T i}_{\mathbf{4}} \mathbf{O}_{\mathbf{1 2}}$ & 7.4672 & 1.34 & 0.64 & 0.70 & 107.82 & 144.01 \\
\hline
\end{tabular}




\begin{tabular}{lllllll}
\hline $\mathbf{C a C u}_{3} \mathbf{T i}_{4} \mathbf{O}_{12}$ & 7.3730 & 1.34 & 0.57 & 0.77 & 108.98 & 141.33 \\
$\mathbf{S r C u}_{3} \mathbf{T i}_{4} \mathbf{O}_{12}$ & 7.4275 & 1.44 & 0.57 & 0.87 & 109.18 & 141.21 \\
\hline
\end{tabular}

Table 3 | Refined structure parameters of PHTO based on NPD data collected at 5 K.

\begin{tabular}{|c|c|c|c|c|c|}
\hline \multicolumn{6}{|c|}{ Crystallographic data for $\mathrm{PbHg}_{3} \mathrm{Ti}_{4} \mathrm{O}_{12}$ based on NPD at $5 \mathrm{~K}$} \\
\hline Atom & Wyck & $\mathrm{x}$ & $\mathrm{y}$ & $\mathrm{z}$ & $U_{\text {iso }}\left(\AA^{2}\right)$ \\
\hline $\mathrm{Pb}$ & $2 \mathrm{a}$ & 0.5 & 0.5 & 0.5 & $0.008(8)$ \\
\hline Hg1 & $2 b$ & 0.5 & 0 & 0.5 & $0.007(1)$ \\
\hline $\mathrm{Hg} 2$ & $2 \mathrm{a}$ & 0.5 & 0.5 & 0 & $0.005(1)$ \\
\hline Hg3 & $2 \mathrm{~b}$ & 0.5 & 0 & 0 & $0.005(4)$ \\
\hline $\mathrm{Ti}$ & $8 \mathrm{e}$ & $0.2353(7)$ & $0.2396(3)$ & $0.2455(8)$ & $0.013(9)$ \\
\hline $\mathrm{O} 1$ & $4 \mathrm{c}$ & $0.1966(0)$ & 0 & $0.2905(6)$ & $0.007(0)$ \\
\hline $\mathrm{O} 2$ & $8 \mathrm{e}$ & $0.2786(9)$ & $0.2103(7)$ & $0.0006(9)$ & $0.013(4)$ \\
\hline $\mathrm{O} 3$ & $4 d$ & 0 & $0.2802(5)$ & $0.2527(9)$ & $0.027(0)$ \\
\hline $\mathrm{O} 4$ & $4 \mathrm{c}$ & $-0.2008(6)$ & 0 & $-0.3022(4)$ & $0.025(1)$ \\
\hline O5 & $4 d$ & 0 & $-0.2696(8)$ & $-0.1963(7)$ & $0.022(2)$ \\
\hline \multicolumn{4}{|c|}{ Bond length $(\AA)$} & \multicolumn{2}{|c|}{ Bond angle $\left({ }^{\circ}\right)$} \\
\hline \multicolumn{2}{|c|}{$\mathrm{Pb}-\mathrm{O} 1: 2.708(6)$} & Ti-O1: $1.901(8)$ & Hg1-O1: 2.853(4) & \multicolumn{2}{|c|}{$\angle \mathrm{Ti}-\mathrm{O} 1-\mathrm{Ti}: 152.07(9)$} \\
\hline \multicolumn{2}{|c|}{$\mathrm{Pb}-\mathrm{O} 2: 2.701(6)$} & Ti-O2: 2.005(6) & Hg1-O3: 2.580(1) & \multicolumn{2}{|c|}{$\angle \mathrm{Ti}-\mathrm{O} 2-\mathrm{Ti}: 157.85(3)$} \\
\hline \multicolumn{2}{|c|}{ Pb-O3: 2.907(2) } & Ti-O3: $1.853(2)$ & Hg1-O5: 2.331(4) & \multicolumn{2}{|c|}{$\angle \mathrm{Ti}-\mathrm{O} 3-\mathrm{Ti}: 160.25(5)$} \\
\hline \multicolumn{2}{|c|}{ Pb-O4: 2.801(7) } & Ti-O4: $2.098(0)$ & Hg2-O1: 2.220(1) & \multicolumn{2}{|c|}{$\angle \mathrm{Ti}-\mathrm{O} 4-\mathrm{Ti}: 145.80(6)$} \\
\hline \multirow{4}{*}{\multicolumn{2}{|c|}{ Pb-O5: $2.569(6)$}} & Ti-O5: 2.102(0) & \multirow{2}{*}{$\begin{array}{l}\text { Hg2-O2: } 2.814(7) \\
\text { Hg2-O4: } 2.179(1)\end{array}$} & \multicolumn{2}{|c|}{$\angle \mathrm{Ti}-\mathrm{O} 5-\mathrm{Ti}: 155.11(8)$} \\
\hline & & & & & \\
\hline & & & $\mathrm{Hg} 3-\mathrm{O} 2: 2.360(5)$ & & \\
\hline & & & Hg3-O3: $2.547(8)$ & & \\
\hline
\end{tabular}

Space group: Imm2 (No. 44) $a=7.7568(9) \AA, b=7.7040(1) \AA, c=7.7019(8) \AA ; \alpha=\beta=\gamma=90^{\circ}$; $V=460.26 \AA^{3} ; \mathrm{Z}=2 ; R_{\mathrm{p}}=4.08 \%, R_{\mathrm{wp}}=3.39 \%$. 

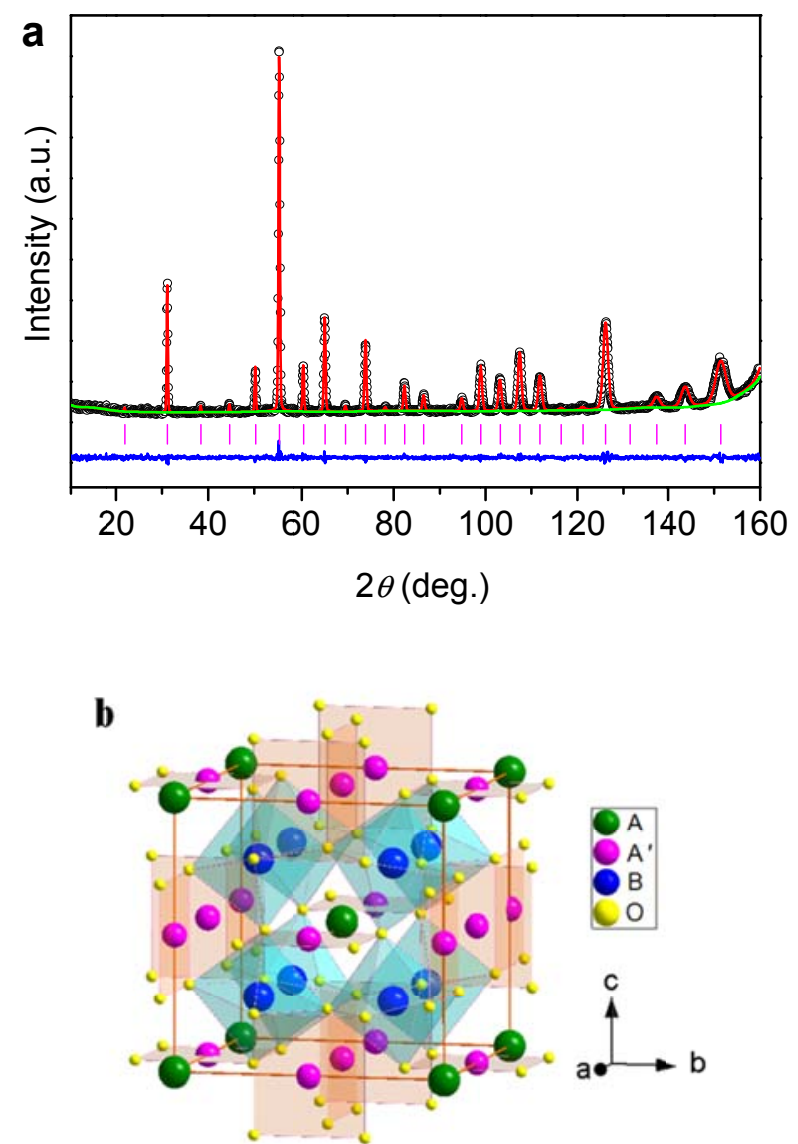

Fig. 1 Neutron diffraction and crystal structure of PHTO. a, Rietveld refinements based on NPD data at $295 \mathrm{~K}$. Observed (crosses), calculated (red), difference (blue) and Bragg reflections (green) are shown in the figure, respectively. The ticks indicate the allowed Bragg reflections with space group Im-3. b, Crystal structure of PHTO. 


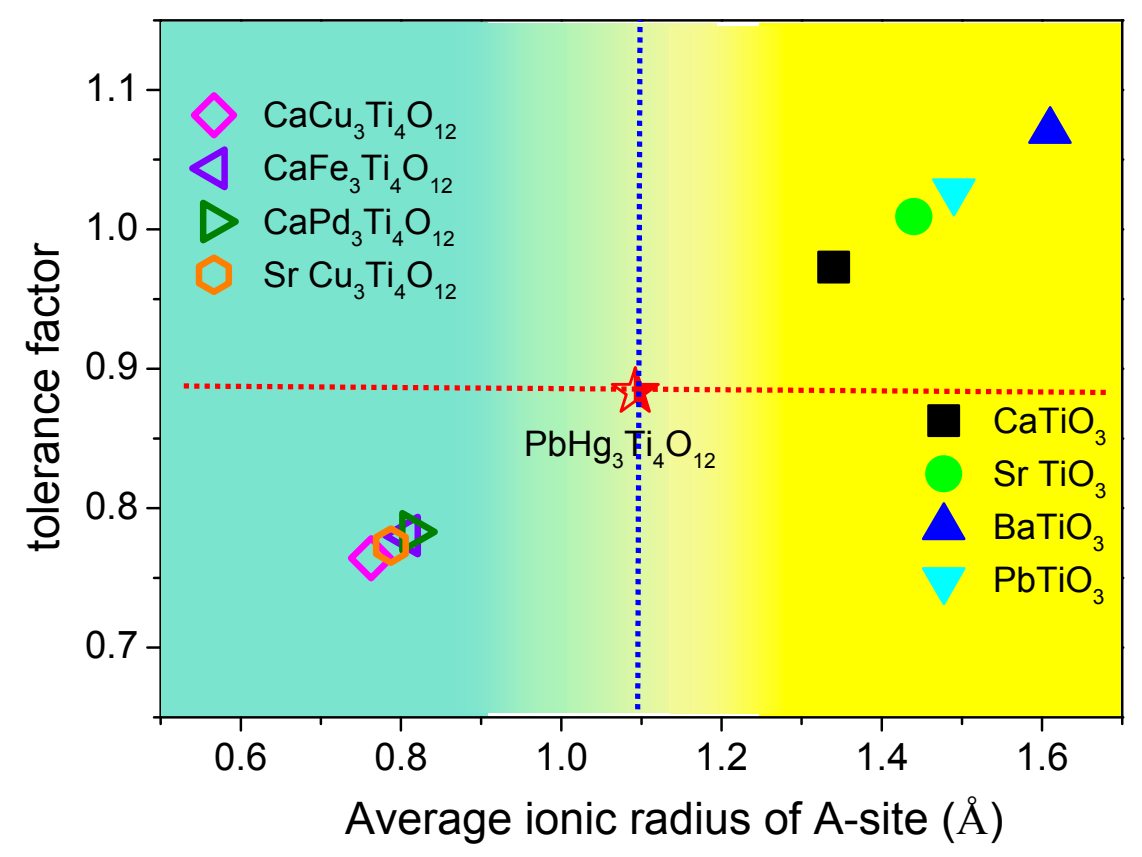

Fig. 2 Tolerance factor $t$ versus average ionic radius of A-site for simple perovskites $\mathrm{ATiO}_{3}$ and $\mathrm{A}$-site-ordered perovskites $\mathrm{AA}_{3}^{\prime} \mathrm{Ti}_{4} \mathrm{O}_{12}$.

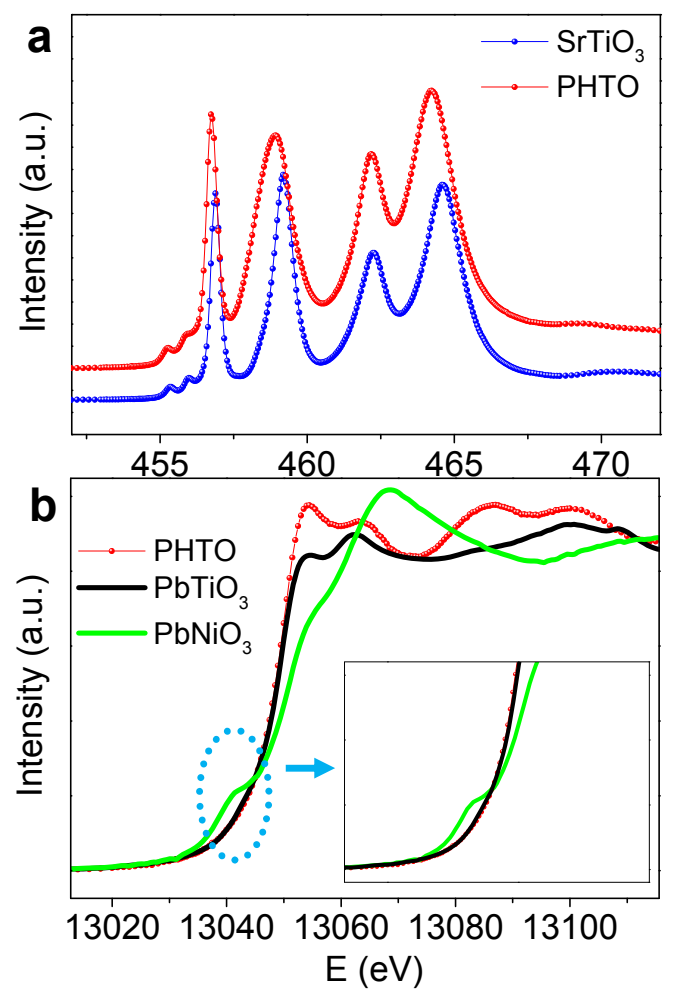

Fig. 3 X-ray absorption spectroscopy of PHTO. a, Ti $L_{2,3}$-edge. b, $\mathrm{Pb} L_{3}$-edge. 

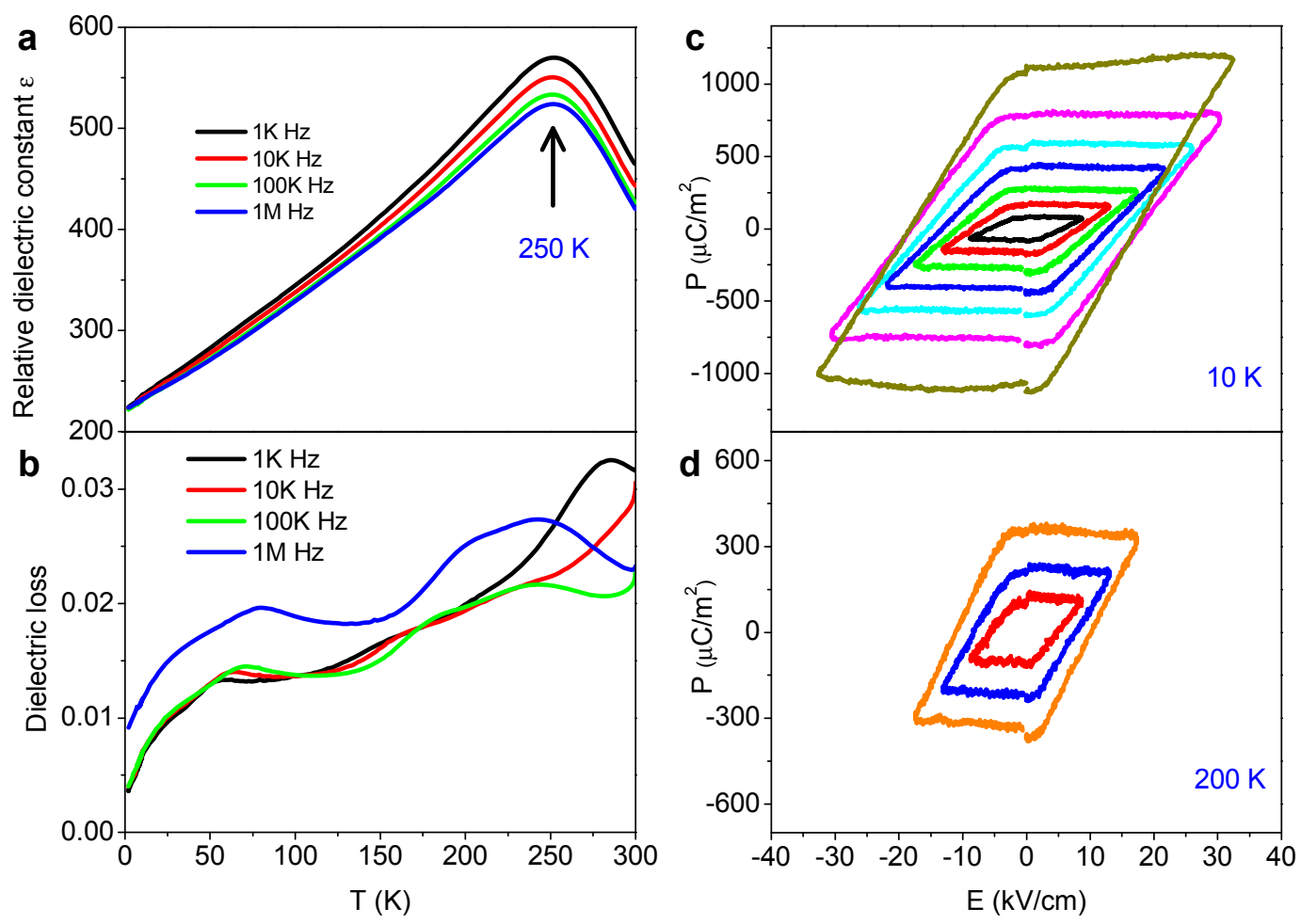

Fig. 4 Dielectricity and ferroelectricity of PHTO. Temperature dependence of a, relative dielectric constant $\varepsilon_{r}$, and $\mathbf{b}$, dielectric loss at selected frequencies. The $P-E$ hysteresis loops measured at c $10 \mathrm{~K}$ and d $200 \mathrm{~K}$ under selected electric fields. 

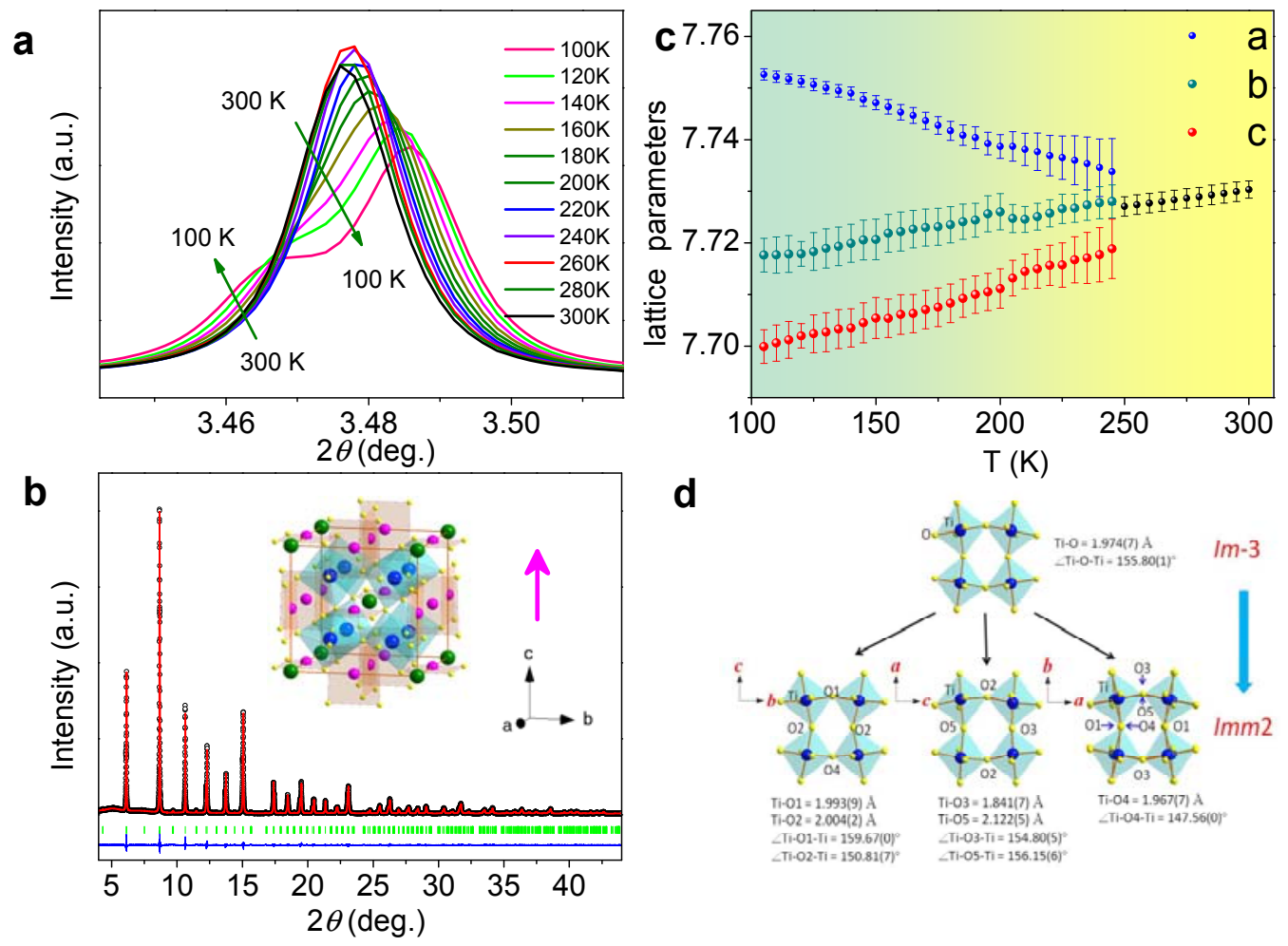

d

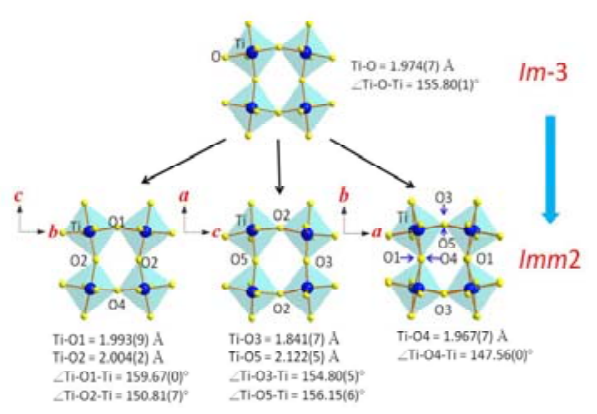

Fig. 5 Temperature induced structural transition in PHTO. a, The characteristic diffraction peaks (400) collected at different temperatures. b, Rietveld refinements based on SXRD data at $90 \mathrm{~K}$. The arrow denotes the polarization direction. c, Temperature dependence of the lattice constant and $\mathbf{d}$ Schematic illustration for the changing of $\mathrm{TiO}_{6}$ octahedron along different axis. 


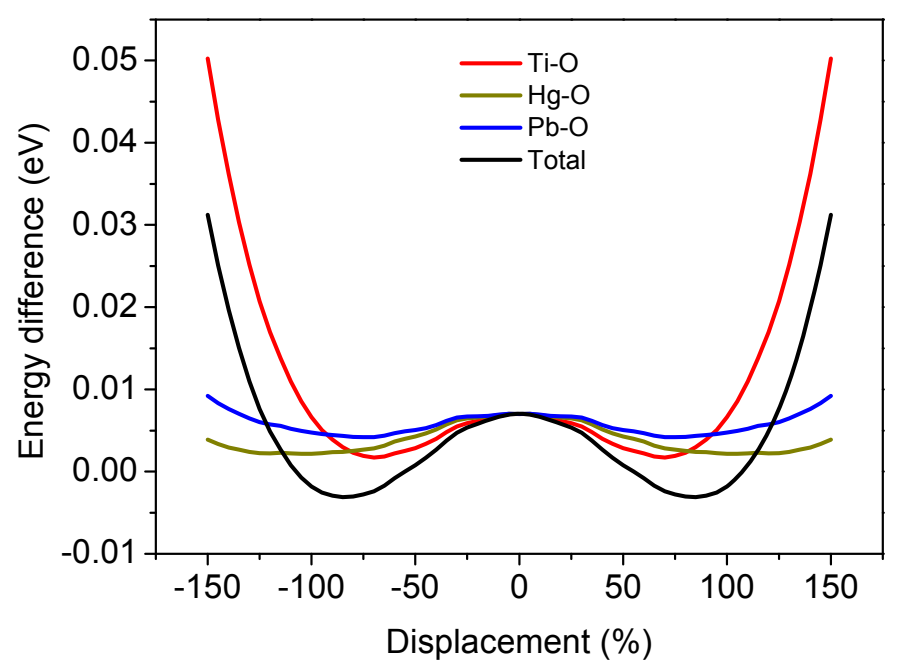

Fig. 6 First principles calculation results of the energy changes with respect to the different moving mode along one of the soft mode on $\Gamma$ point. The red, yellow, blue lines correspond to Ti-O displacements only, $\mathrm{Hg}-\mathrm{O}$ displacements only and $\mathrm{Pb}-\mathrm{O}$ displacements only. The black line corresponds to all atoms displacements. The double well structure of the graph indicates the spontaneous structure phase transition. 


\section{Supporting Information for the manuscript:}

\section{Experimental and theoretical section}

The magnetic susceptibility was measured by using a vibrating sample magnetometer (VSM) of a Quantum Design MPMS system. The electrical transport properties are studied using a Quantum Design Physical Properties Measurement System (PPMS) by standard four-probe method. The thermal stability of the sample was measured by thermogravimetry analysis from room temperature to $1473 \mathrm{~K}$ at a heating rate of $10 \mathrm{~K} \mathrm{~min}^{-1}$, using a LABSYS EVO TGA system. Diffuse-reflectance spectra were measured at room temperature using a UV-Vis-NIR spectrophotometer.

First principles calculation was performed by using the Vienna ab initio simulation package (VASP) ${ }^{1,2}$, which implements the density functional theory with generalized gradient approximation (GGA) ${ }^{3}$ of Perdew-Burke-Ernzerhof (PBE) type to exchange-correlation functional. Electronic band structure was calculate with plane wave cutoff of $700 \mathrm{eV}$ and a $7 \times 7 \times 7$ Monkhorst-Pack k-point mesh. The phonon band structure were calculated by using the density functional perturbation theory (DFPF) performed with the VASP and PHONOPY package ${ }^{4}$. A $2 \times 2 \times 2$ supercell of 160 atoms was used here. We also checked the phonon band result using the ALAMODE package ${ }^{5}$, which gave a same result. All these calculations were done after a careful optimization with the given symmetry until the residual Hellmann-Feynman forces became smaller than $10^{-4} \mathrm{eV} \AA^{-1}$.

\section{REFERENCES}

1 Kresse, G. \& Furthmuller, J. Efficient iterative schemes for ab initio total-energy calculations using a plane-wave basis set. Phys. Rev. B 54, 11169-11186 (1996).

2 Kresse, G. \& Joubert, D. From ultrasoft pseudopotentials to the projector augmented-wave method. Phys. Rev. B 59, 1758-1775 (1999).

3 Perdew, J. P., Burke, K. \& Ernzerhof, M. Generalized gradient approximation made simple. Phys. Rev. Lett. 77, 3865-3868 (1996).

4 Togo, A., Oba, F. \& Tanaka, I. First-principles calculations of the ferroelastic transition between rutile-type and $\mathrm{CaCl}_{2}$-type $\mathrm{SiO}_{2}$ at high pressures. Phys. Rev. B 78, 134106 (2008).

5 Tadano, T., Gohda, Y. \& Tsuneyuki, S. Anharmonic force constants extracted from first-principles molecular dynamics: applications to heat transfer simulations. J. Phys.: Condens. Matter 26, 225402 (2014). 
Table S1 | Refined structure parameters of PHTO based on SXRD data collected at $300 \mathrm{~K}$.

\begin{tabular}{ll}
\hline & SXRD \\
\hline $\mathrm{a}(\AA)$ & $7.7234(9)$ \\
$\mathrm{Z}$ & 2 \\
Formula weight & 1192.56 \\
Cacl. Density $\left(\mathrm{g} / \mathrm{cm}^{3}\right)$ & $8.5958(9)$ \\
$\mathrm{V}\left(\AA^{3}\right)$ & $460.72(5)$ \\
$\mathrm{O}_{\mathrm{y}}$ & $0.7069(2)$ \\
$\mathrm{O}_{\mathrm{z}}$ & $0.2181(0)$ \\
$U_{\text {iso }}(\mathrm{Pb})\left(\AA^{2}\right)$ & $0.011(4)$ \\
$U_{\text {iso }}(\mathrm{Hg})\left(\AA^{2}\right)$ & $0.009(7)$ \\
$U_{\text {iso }}(\mathrm{Ti})\left(\AA^{2}\right)$ & $0.004(0)$ \\
$U_{\text {iso }}(\mathrm{O})\left(\AA^{2}\right)$ & $0.003(2)$ \\
$\mathrm{Pb}-\mathrm{O}(\times 12)(\AA)$ & $2.821(6)$ \\
$\mathrm{Hg}-\mathrm{O}(\times 4)(\AA)$ & $2.322(1)$ \\
$\mathrm{Hg}-\mathrm{O}(\times 4)(\AA)$ & $2.700(8)$ \\
$\mathrm{Ti}-\mathrm{O}(\times 6)(\AA)$ & $1.974(7)$ \\
$\angle \mathrm{Ti}-\mathrm{O}-\mathrm{Ti}\left({ }^{\circ}\right)$ & $155.80(1)$ \\
$\mathrm{BVS}(\mathrm{Pb})$ & 1.76 \\
$\mathrm{BVS}(\mathrm{Hg})$ & 2.11 \\
$\mathrm{BVS}(\mathrm{Ti})$ & 3.90 \\
$\mathrm{R}_{\mathrm{wp}}(\%)$ & 8.47 \\
$\mathrm{R}_{\mathrm{p}}(\%)$ & 6.79
\end{tabular}

${ }^{a}$ The BVS values $\left(V_{i}\right)$ were calculated using the formula $V_{i}=\Sigma_{j} S_{i j}$, and $\left.S_{i j}=\exp \left[\left(r_{0}-r_{i j}\right) / 0.37\right)\right]$. In PHTO, $r_{0}=2.112$ for $\mathrm{Pb}, 1.972$ for $\mathrm{Hg}$ and 1.815 for Ti. For the A-site $\mathrm{Pb}, 12$-coordinated oxygen atoms were used. For the $\mathrm{A}^{\prime}$-site $\mathrm{Hg}, 8$-coordinated oxygen atoms were used. For the B-site Ti, 6-coordinated oxygen atoms were used. ${ }^{b}$ Space group: Im-3; Atomic sites: $\mathrm{Pb} 2 a(0,0,0), \mathrm{Hg} 6 b$ $(0,0.5,0.5)$, Ti $8 c(0.25,0.25,0.25), \mathrm{O} 24 g(0, y, \mathrm{z})$. 
Table S2 | Refined structure parameters of PHTO based on SXRD data collected at $90 \mathrm{~K}$.

\begin{tabular}{|c|c|c|c|c|c|}
\hline \multicolumn{6}{|c|}{ Crystallographic data for $\mathrm{PbHg}_{3} \mathrm{Ti}_{4} \mathrm{O}_{12}$ based on SXRD at $90 \mathrm{~K}$} \\
\hline Atom & Wyck & $\mathrm{x}$ & $\mathrm{y}$ & $\mathrm{z}$ & $U_{\text {iso }}\left(\AA^{2}\right)$ \\
\hline $\mathrm{Pb}$ & $2 \mathrm{a}$ & 0.5 & 0.5 & 0.5 & $0.008(9)$ \\
\hline Hg1 & $2 b$ & 0.5 & 0 & 0.5 & $0.007(1)$ \\
\hline Hg2 & $2 \mathrm{a}$ & 0.5 & 0.5 & 0 & $0.005(1)$ \\
\hline Hg3 & $2 \mathrm{~b}$ & 0.5 & 0 & 0 & $0.005(4)$ \\
\hline $\mathrm{Ti}$ & $8 \mathrm{e}$ & $0.2319(7)$ & $0.2547(5)$ & $0.2295(1)$ & $0.016(2)$ \\
\hline $\mathrm{O} 1$ & $4 \mathrm{c}$ & $0.2125(1)$ & 0 & $0.2707(9)$ & $0.002(4)$ \\
\hline $\mathrm{O} 2$ & $8 \mathrm{e}$ & $0.2872(7)$ & $0.1966(5)$ & $-0.0179(9)$ & $0.010(4)$ \\
\hline $\mathrm{O} 3$ & $4 \mathrm{~d}$ & 0 & $0.3061(7)$ & $0.2208(8)$ & $0.005(1)$ \\
\hline $\mathrm{O} 4$ & $4 \mathrm{c}$ & $-0.1982(8)$ & 0 & $-0.2835(1)$ & $0.005(0)$ \\
\hline $\mathrm{O} 5$ & $4 d$ & 0 & $-0.2942(1)$ & $-0.2414(7)$ & $0.001(7)$ \\
\hline \multicolumn{3}{|c|}{ Bond length (Å) } & \multicolumn{3}{|c|}{ Bond angle $\left({ }^{\circ}\right)$} \\
\hline \multicolumn{2}{|c|}{ Pb-O1: 2.657(1) } & Ti-O1: 1.993(9) & Hg1-O1: 2.842(1) & \multicolumn{2}{|c|}{$\angle \mathrm{Ti}-\mathrm{O} 1-\mathrm{Ti}: 159.67(0)$} \\
\hline \multicolumn{2}{|c|}{$\mathrm{Pb}-\mathrm{O} 2: 2.696(1)$} & Ti-O2: 2.004(2) & Hg1-O3: 2.263(5) & \multicolumn{2}{|c|}{$\angle \mathrm{Ti}-\mathrm{O} 2-\mathrm{Ti}: 150.81(7)$} \\
\hline \multicolumn{2}{|c|}{$\mathrm{Pb}-\mathrm{O} 3: 2.908(2)$} & Ti-O3: 1.841(7) & Hg1-O5: 2.443(7) & \multicolumn{2}{|c|}{$\angle \mathrm{Ti}-\mathrm{O} 3-\mathrm{Ti}: 154.80(5)$} \\
\hline \multicolumn{2}{|c|}{ Pb-O4: 2.669(8) } & Ti-O4: 1.967(7) & Hg2-O1: 2.411(4) & \multicolumn{2}{|c|}{$\angle \mathrm{Ti}-\mathrm{O} 4-\mathrm{Ti}: 147.56(0)$} \\
\hline \multirow{4}{*}{\multicolumn{2}{|c|}{$\mathrm{Pb}-\mathrm{O} 5: 2.931(9)$}} & Ti-O5: 2.122(5) & Hg2-O4: 2.267(1) & \multicolumn{2}{|c|}{$\angle \mathrm{Ti}-\mathrm{O} 5-\mathrm{Ti}: 156.15(6)$} \\
\hline & & & \multirow{2}{*}{\multicolumn{3}{|c|}{$\begin{array}{l}\mathrm{Hg} 3-\mathrm{O} 2: 2.243(0) \\
\mathrm{Hg} 3-\mathrm{O} 3: 2.617(4)\end{array}$}} \\
\hline & & & & & \\
\hline & & & \multicolumn{3}{|l|}{ Hg3-O5: $2.545(1)$} \\
\hline
\end{tabular}

Space group: Imm2（No. 44） $a=7.7483(9) \AA, b=7.7042(4) \AA, c=7.7014(2) \AA ; \alpha=\beta=\gamma=90^{\circ}$; $V=459.740 \AA^{3} ; \mathrm{Z}=2 ; R_{\mathrm{p}}=5.34 \%, R_{\mathrm{wp}}=6.95 \%$. 


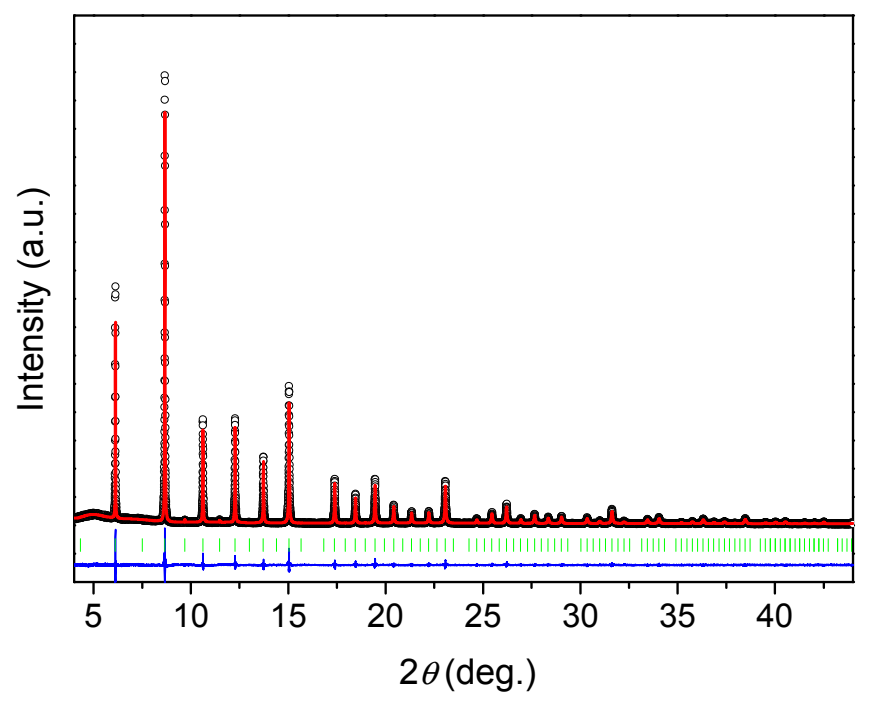

Fig. S1 Rietveld refinements of SXRD patterns for at 300 K PHTO. Observed (crosses), calculated (red), difference (blue) and Bragg reflections (green) are shown in the figure, respectively. The ticks indicate the allowed Bragg reflections with space group $I m-3$.

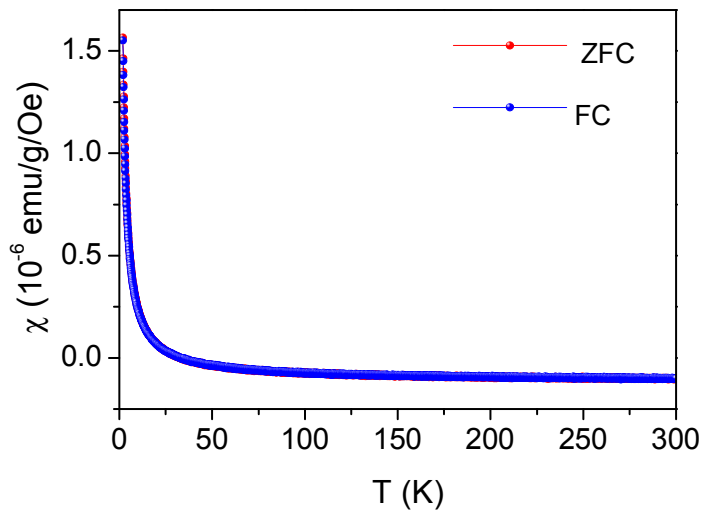

Fig. S2 Temperature dependent magnetic susceptibility $\chi$ for PHTO with external magnetic field of $0.1 \mathrm{~T}$. 

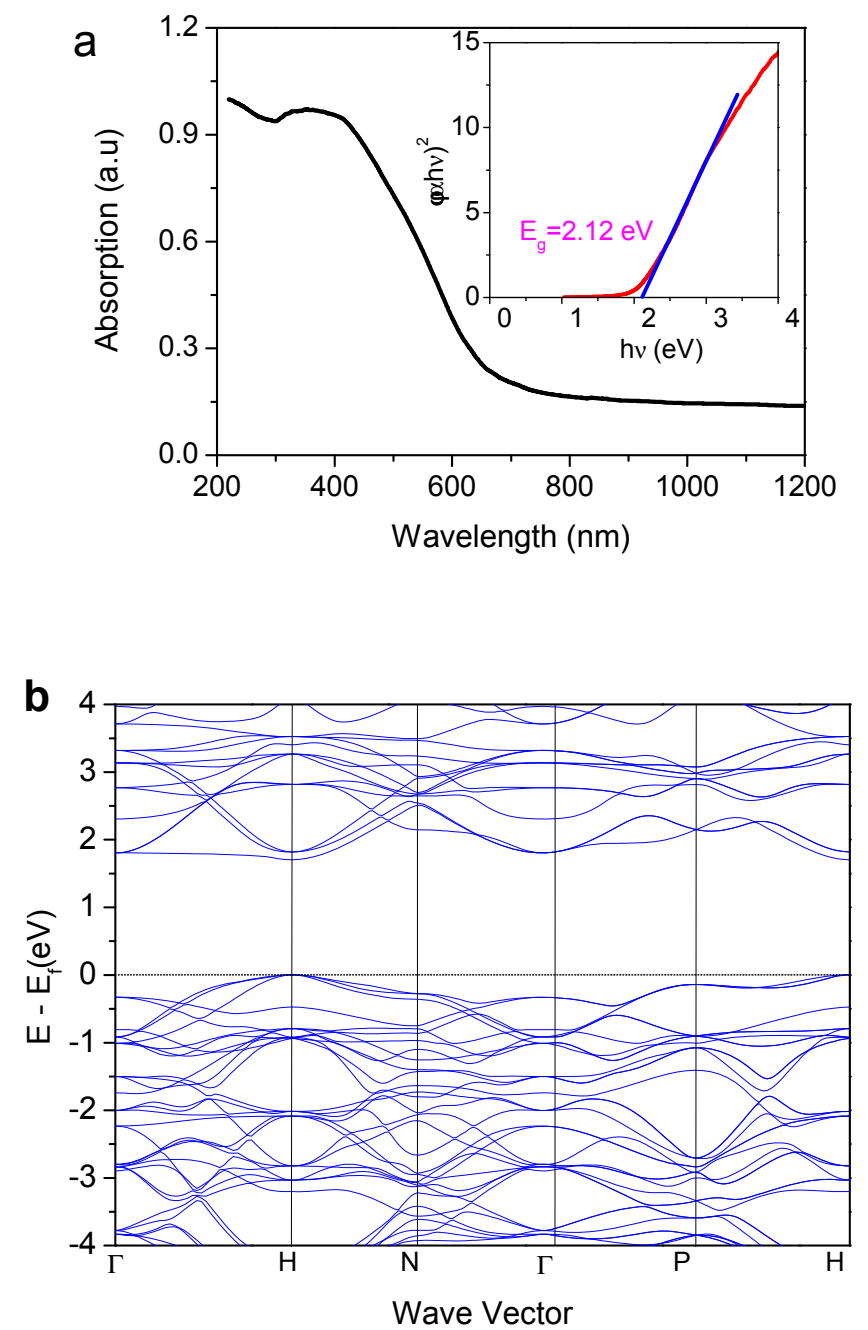

Fig. S3 a, UV-Vis-NIR diffuse reflectance spectrum of PHTO measured at room temperature. b, First-principle calculation of PHTO band structures. 


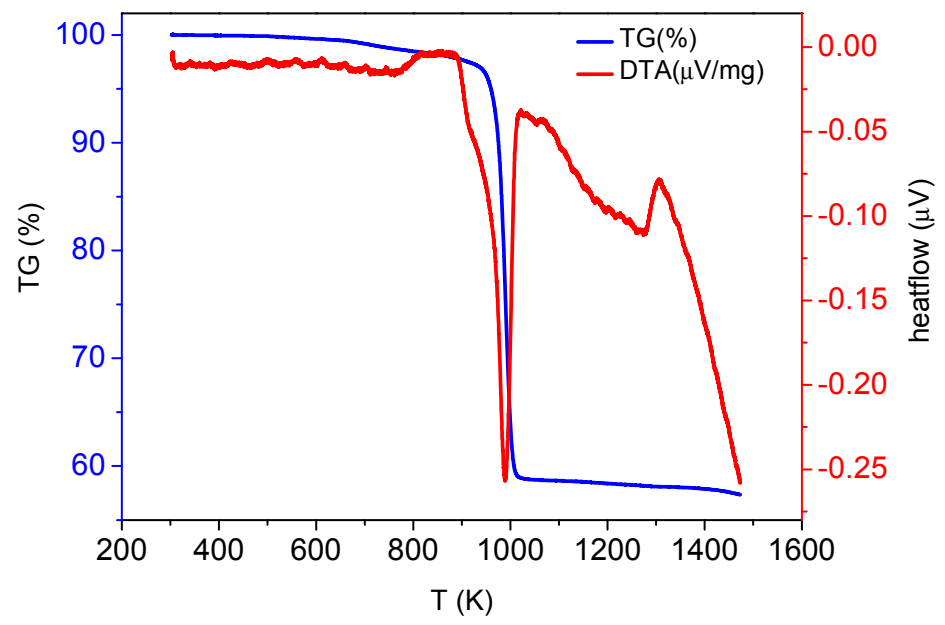

Fig. S4 Thermogravimetry analysis of PHTO. The TGA measurement results show that the sample decomposed at about $973 \mathrm{~K}$, losing about $40 \%$ of its mass. The residual products were $\mathrm{TiO}_{2}$ and $\mathrm{PbO}$, so the decomposition reaction was $\mathrm{PbHg}_{3} \mathrm{Ti}_{4} \mathrm{O}_{12} \rightarrow \mathrm{PbO}+3 \mathrm{HgO}+4 \mathrm{TiO}_{2}$. The observed weight loss agrees well with the $\mathrm{HgO}$, which evaporates into the air at high temperature.

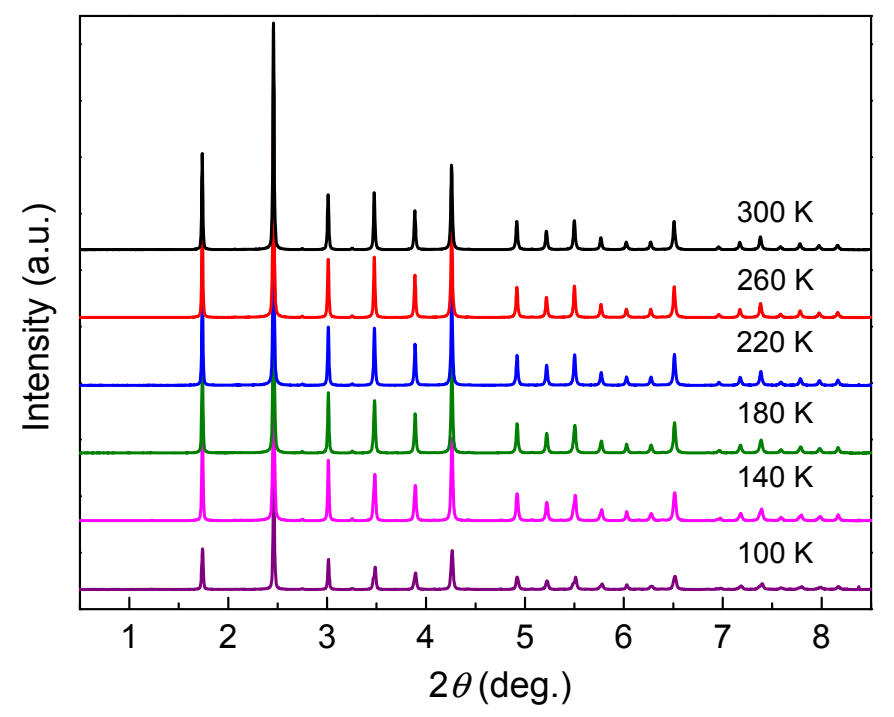

Fig. S5 Temperature dependence of SXRD patterns of PHTO obtained from $300 \mathrm{~K}$ to $100 \mathrm{~K}$. 

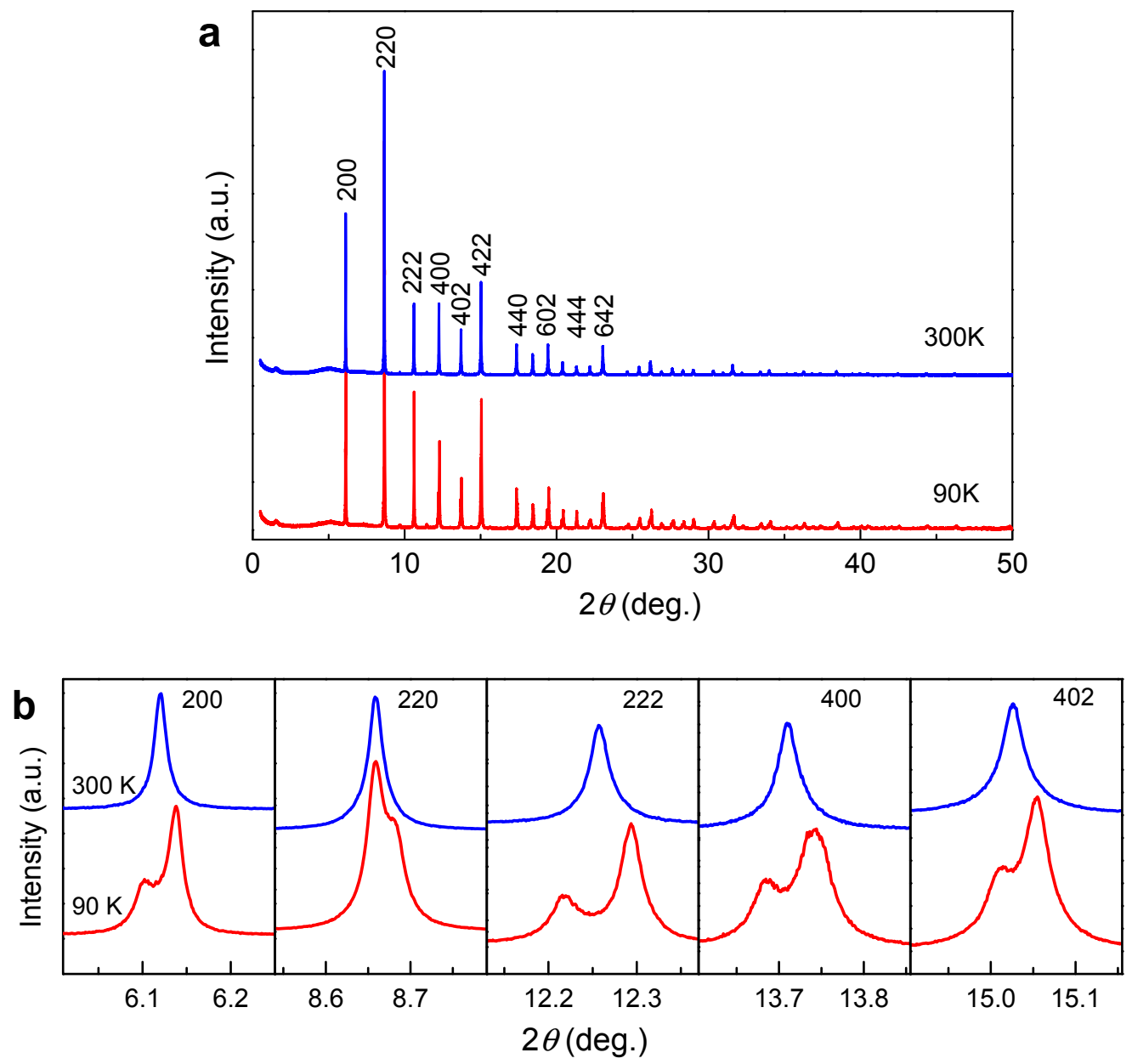

Fig. S6 a SXRD patterns of PHTO obtained at $300 \mathrm{~K}$ and $90 \mathrm{~K}$. b, Some characteristic diffraction peaks collected at $300 \mathrm{~K}$ and $90 \mathrm{~K}$.

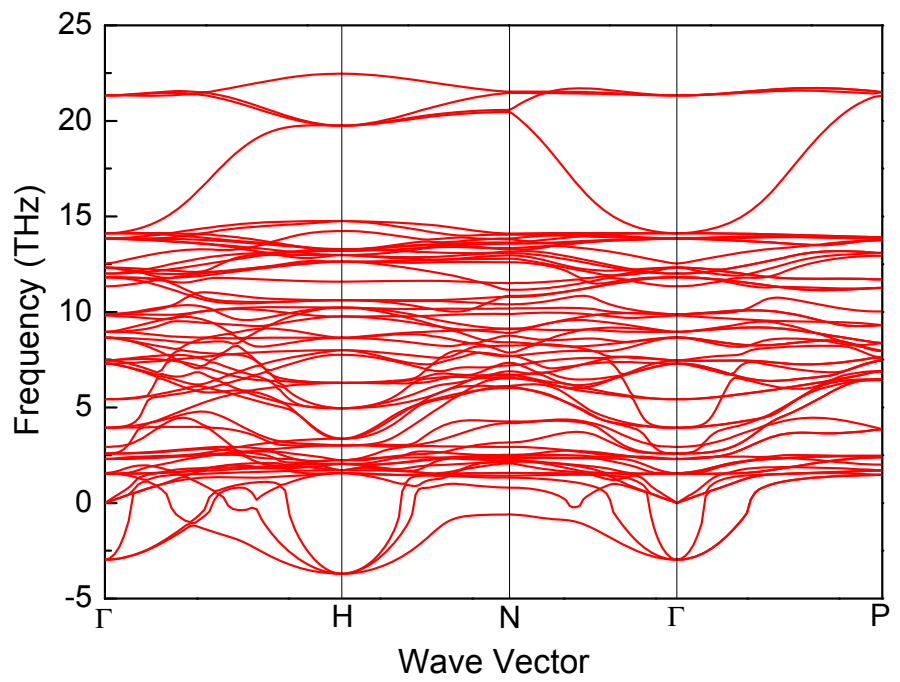

Fig. S7 The phonon band calculated by using the DFPT method. 
Figures
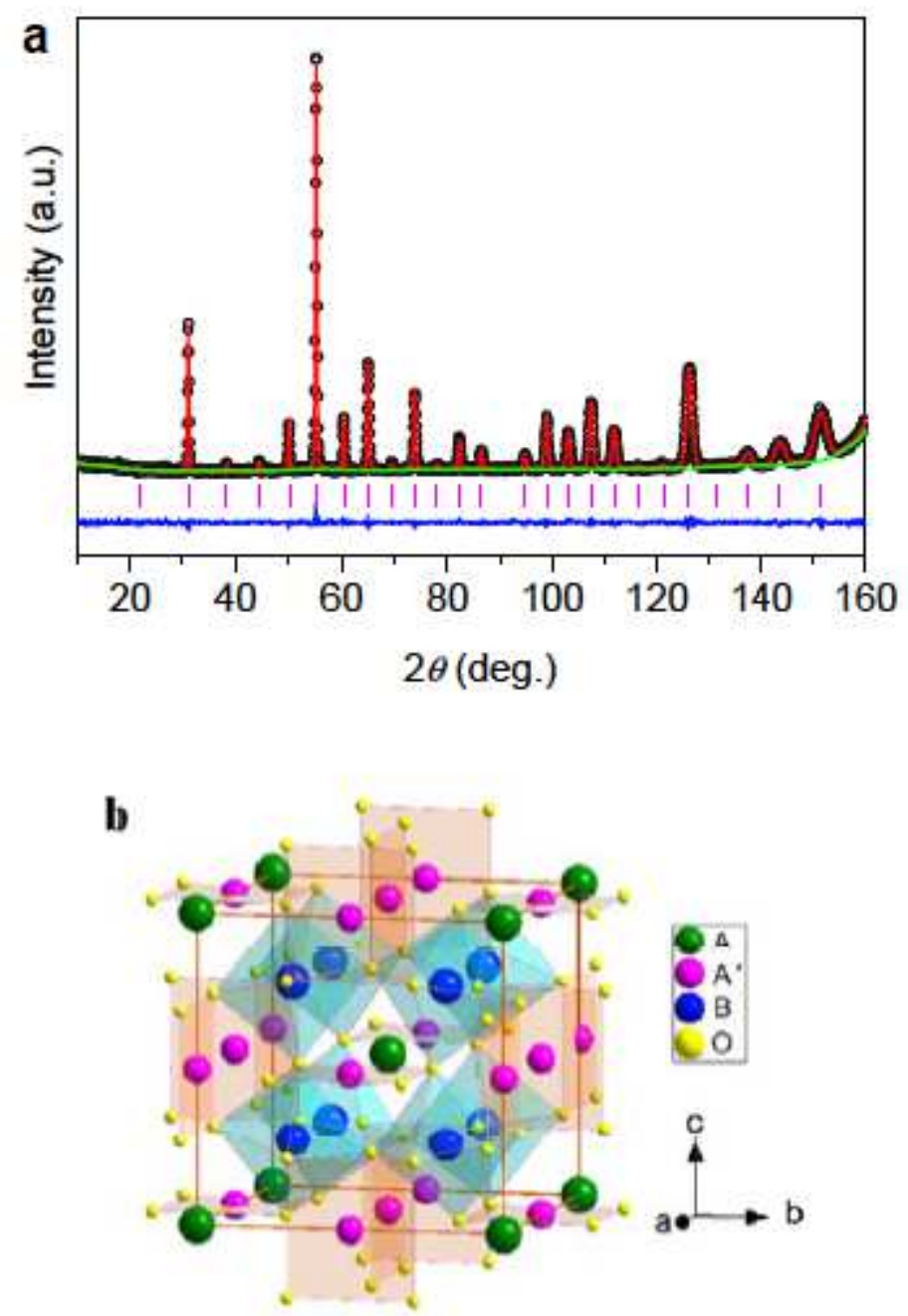

\section{Figure 1}

Neutro diffraction and crystal structure of PHTO. a, Rietveld refinements based on NPD data at $295 \mathrm{~K}$. Observed (crosses,) calculated (red), difference (blue) and Bragg reflections (green) are shown in the figure, respectively. The ticks indicate the allowed Bragg reflections with space group Im-3. b, Crystal structure of PHTO. 


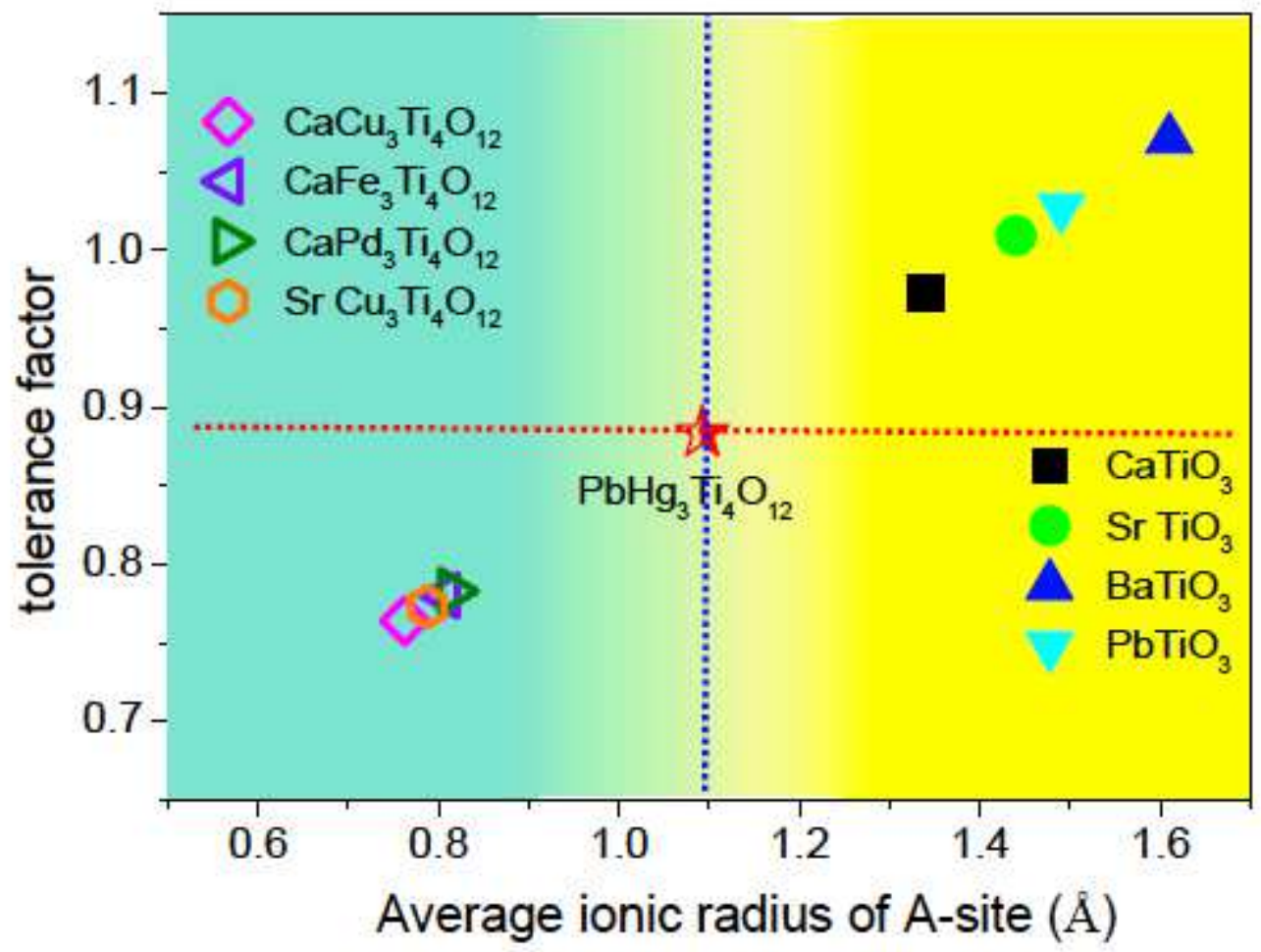

Figure 2

Tolerance factor $t$ versus average ionic radius of A-site for simple perovskites ATiO3 and A-site-ordered perovskites AA'3Ti4012. 

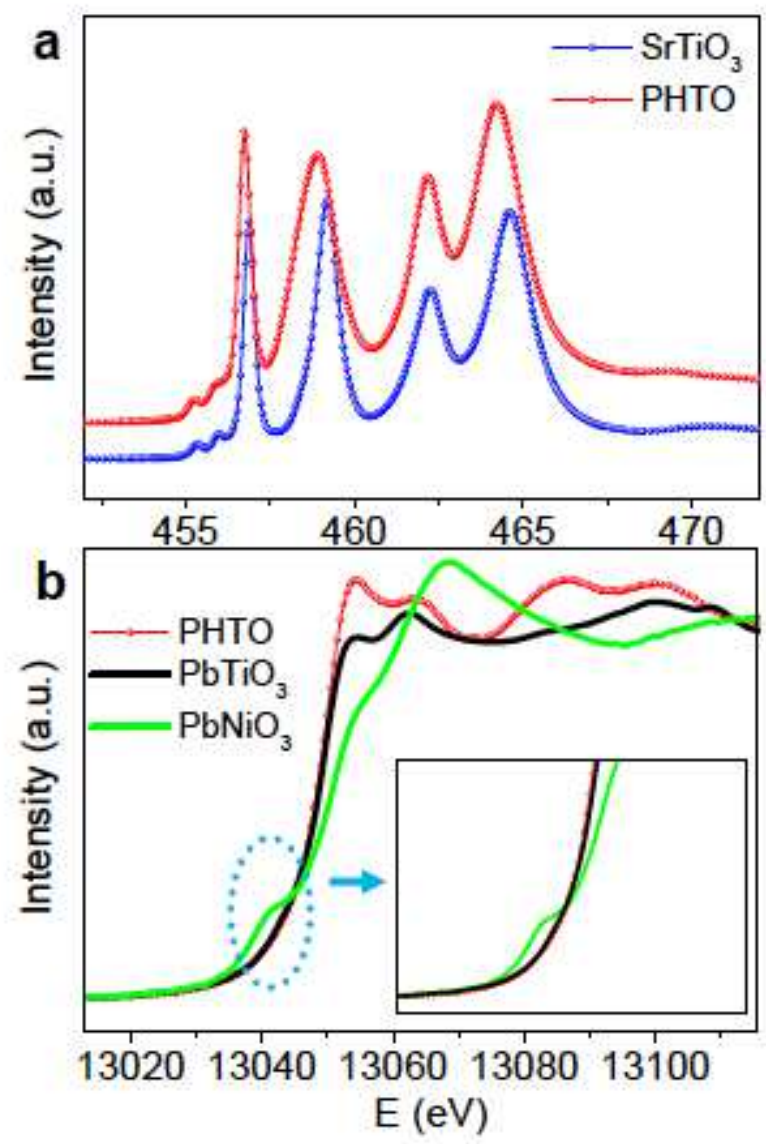

Figure 3

X-ray absorption spectroscopy of PHTO. a, Ti L2,3-edge. b, Pb L3-edge. 

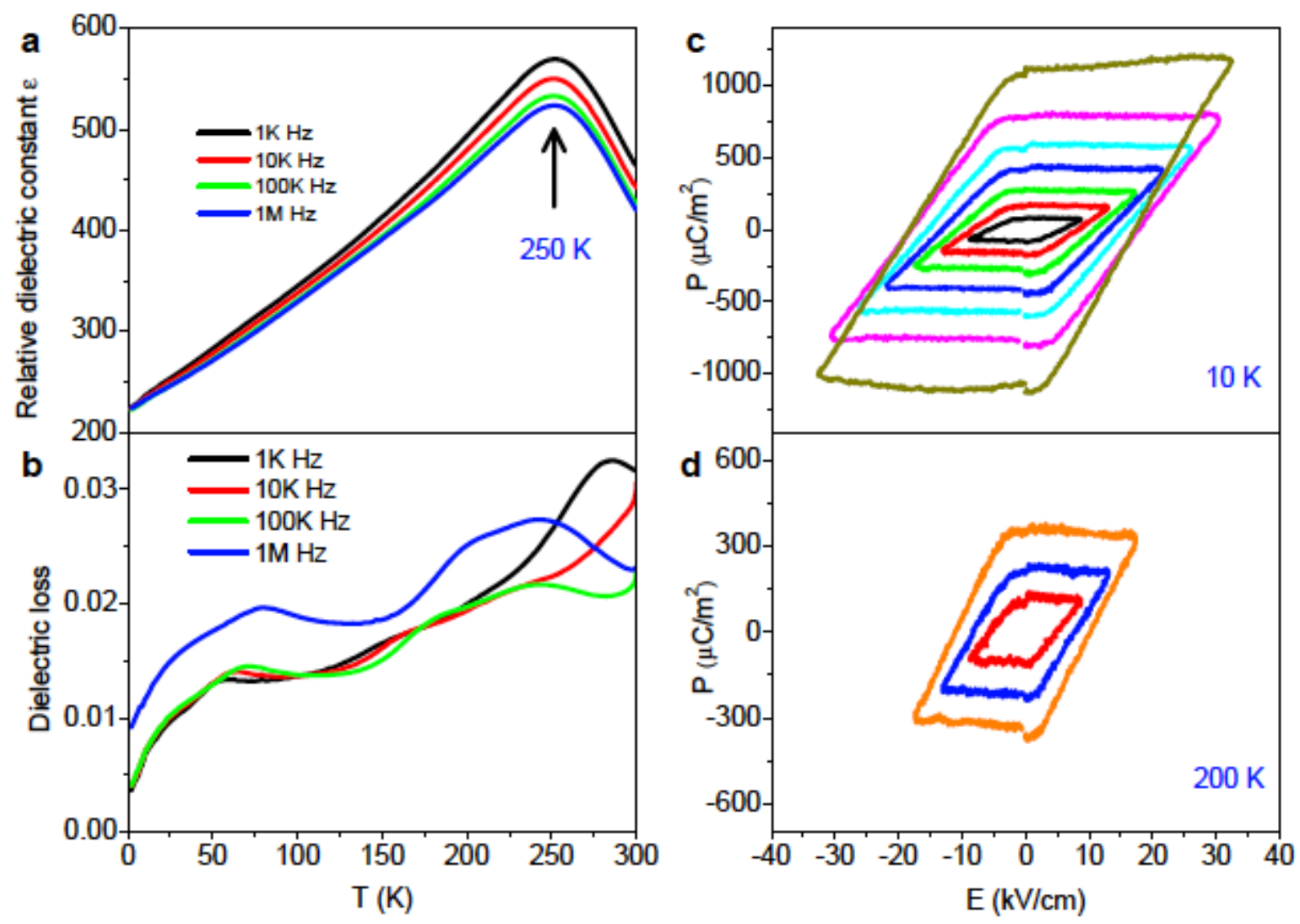

Figure 4

Dielectricity and ferroelectricity of PHTO. Temperature dependence of a, relative dielectric constant $\varepsilon$ r, and b, dielectric loss at selected frequencies. The P-E hysteresis loops measured at c $10 \mathrm{~K}$ and d $200 \mathrm{~K}$ under selected electric fields. 

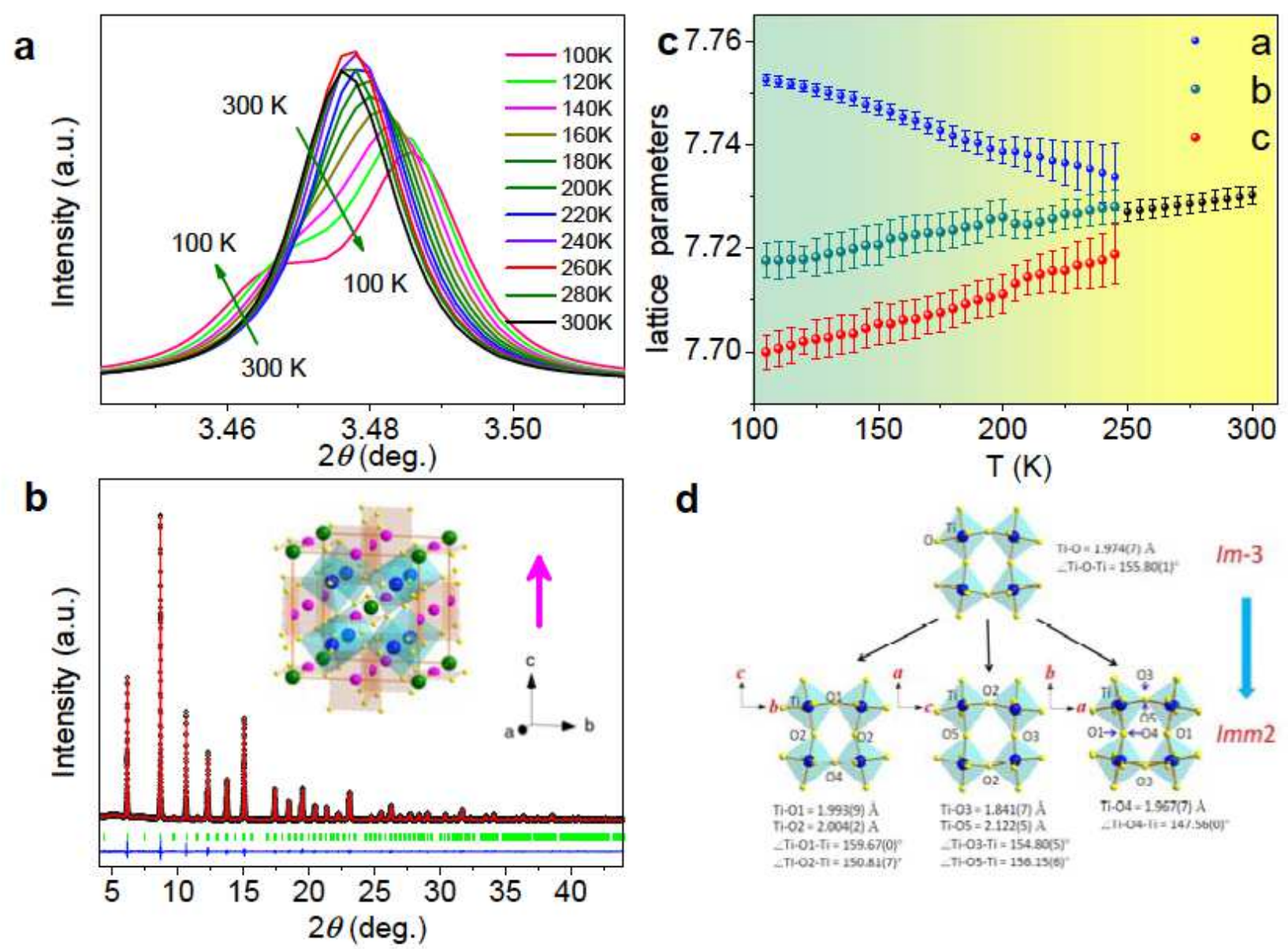

d

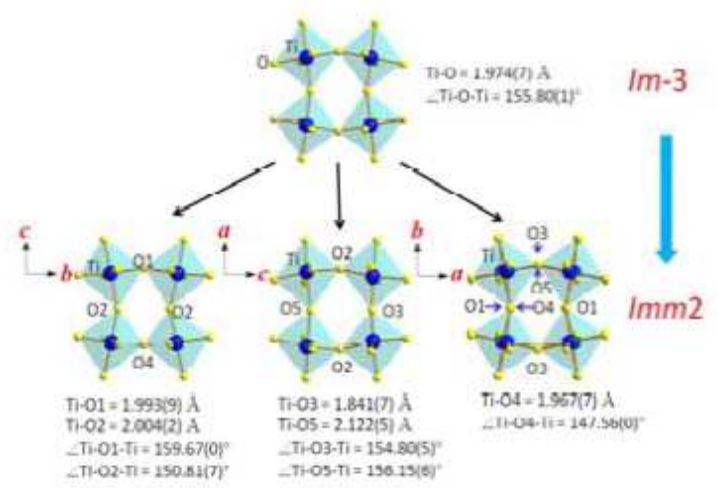

Figure 5

Temperature induced structural transition in PHTO. a, The characteristic diffraction peaks (400) collected at different temperatures. b, Rietveld refinements based on SXRD data at $90 \mathrm{~K}$. The arrow denotes the polarization direction. $c$, Temperature dependence of the lattice constant and d Schematic illustration for the changing of TiO6 octahedron along different axis. 


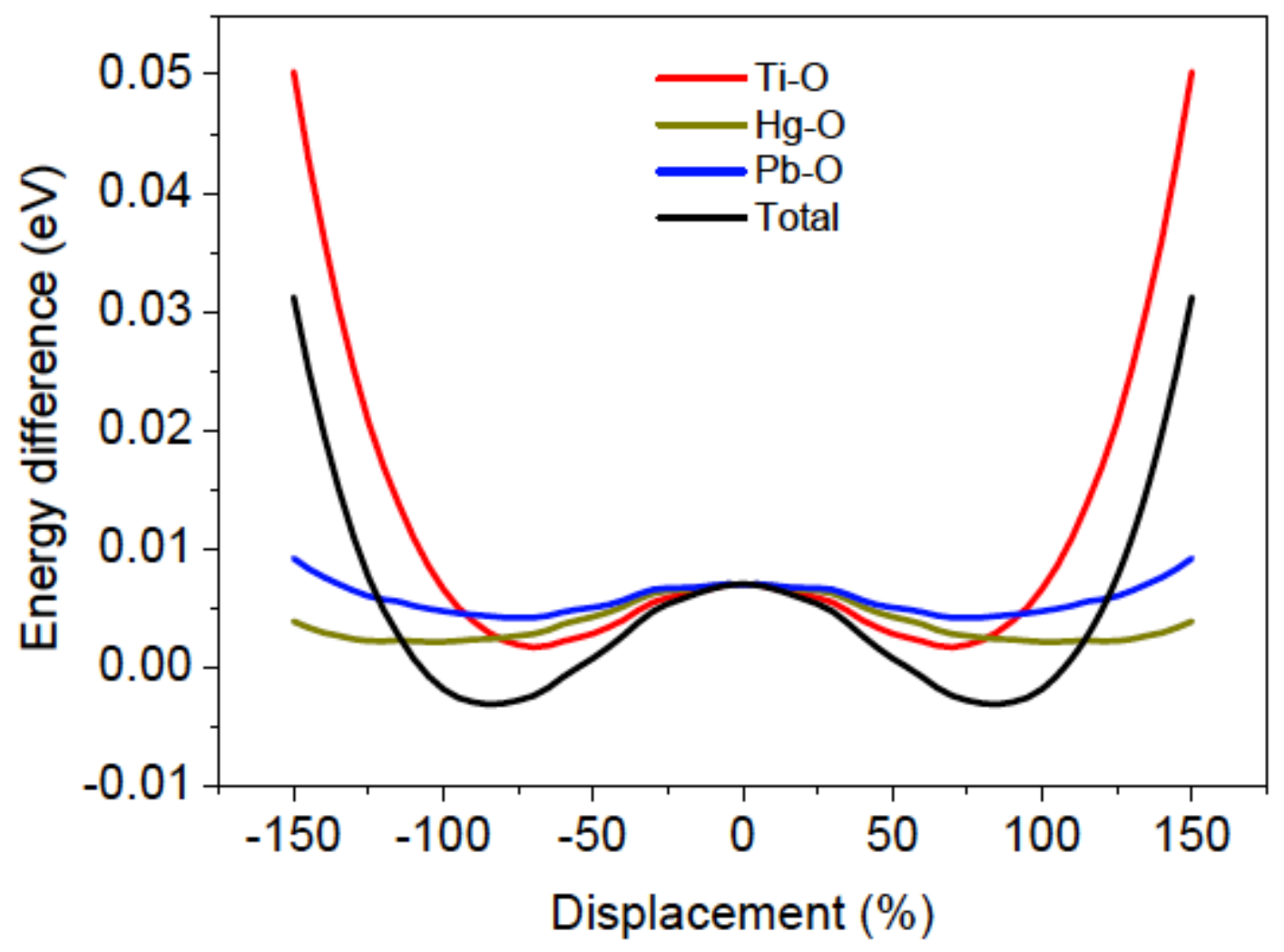

Figure 6

First principles calculation results of the energy changes with respect to the different moving mode along one of the soft mode on $\Gamma$ point. The red, yellow, blue lines correspond to Ti-O displacements only, $\mathrm{Hg}-\mathrm{O}$ displacements only and $\mathrm{Pb}-\mathrm{O}$ displacements only. The black line corresponds to all atoms displacements. The double well structure of the graph indicates the spontaneous structure phase transition. 